\title{
Arqueologia da paisagem urbana: lógicas, ritmos e atores na construção do centro histórico de São Paulo (I809-I942)
}

\author{
[ Archaeology of cityscape: logics, rhythms and makers \\ in São Paulo old-town fabric (I809-I942)
}

\section{Beatriz Piccolotto Siqueira Bueno ${ }^{x}$}

Apoio financeiro: $\mathrm{CNPq}$ (Bolsa de Produtividade em Pesquisa - $\mathrm{PQ} 2$ e Projeto Universal I4/20I2).Bolsistas: Marcos Calixto Rios (Fapesp), Marina Gonçalves Marques (CNPq) e Sheila Schneck (CNPq).

\begin{abstract}
RESUMO-Sistemas de Informações Geográficas (SIGs) permitem reconstituir paisagens urbanas na longa duração. Os SIGs Históricos são fundamentais na espacialização de banco de dados complexos, viabilizando a elaboração de cartografias regressivas e temáticas - quadra a quadra, rua a rua, lote a lote -, cruzando informações textuais e visuais. Propomo-nos a demonstrar nossa metodologia e a linha teórica que a alicerça, bem como evidenciar os resultados adquiridos, desenvolvendo novas pistas de pesquisa e contribuindo para uma melhor compreensão do processo, das dinâmicas e ritmos de produção social da cidade do ponto de vista da sua dimensão material.•PALAVRAS-CHAVE - Arqueologia da paisagem; mercado imobiliá-
\end{abstract}

rio; história da urbanização; São Paulo. • ABSTRACT · Geo-historical Information Systems (GISs) may be used to reconstitute long-term cityscapes and are crucial when spatializing complex databases to develop regressive thematic cartographies - block by block, street by street, lot by lot - and to compare textual and visual information. We propose to demonstrate our methods, theoretical approaches and results acquired, developing new paths for research and adding to our comprehension of the process, dynamics and rhythms of social production of cities from the point of view of their material aspects. $\cdot$ KEYWORDS · Archaeology of cityscape; property market; history of urbanization; São Paulo.

Recebido em I8 de abril de 2016

Aprovado em I9 de julho de 2016

BUENO, Beatriz Piccolotto Siqueira, Arqueologia da paisagem urbana: lógicas, ritmos e atores na construção do centro histórico de São Paulo (I809-I942). Revista do Instituto de Estudos Brasileiros, Brasil, n. 64, p 99-I30 ago.2016

DOI: http://dx.doi.org/Io.II606/isnn.23I6-90IX.voi64p99-I30

I Universidade de São Paulo (USP, São Paulo, SP, Brasil) 


\section{RUGOSIDADES DO PROCESSO DE URBANIZAÇÃo}

O estudo da urbanização ${ }^{2}$ do centro histórico de São Paulo aqui em foco tem algumas peculiaridades. Foge da perspectiva em voo de pássaro mais habitual e aproxima a lente nas ações individuais, atentando para o papel da arquitetura comum na composição da tessitura urbana e buscando aquilatar suas lógicas de produção, dinâmicas, ritmos e temporalidades. Para tanto elegemos a colina entre os rios Tamanduateí e Anhangabaú como recorte espacial, com vistas a entrever o processo de acumulações e substituições sucessivas decorrentes da ação de diferentes gerações num curto período de tempo.

O estudo parte da premissa de que os fragmentos materiais da paisagem urbana contemporânea oferecem pistas que permitem supor seu caráter histórico3. Mais do que um palimpsesto 4 , a paisagem é um precioso instrumento de trabalho, na medida em que, como salienta Fernand Braudel ${ }^{5}$, é como nossa pele condenada a conservar a cicatriz das feridas antigas. Como acumulação desigual de tempos, as rugosidades dos sucessivos passados amalgamados na paisagem atual permitem supor cada etapa do

2 Campo disciplinar inaugurado por Nestor Goulart Reis Filho na Faculdade de Arquitetura e Urbanismo da Universidade de São Paulo, do qual somos seguidores. Cf. REIS, Nestor G. Notas sobre a evolução dos estudos de história da urbanização e do urbanismo. Cadernos de Pesquisa do LAP, n. 29, I999.

3 Sobre o conceito de paisagem, ver: SANTOS, Milton. A natureza do espaço. Técnica e tempo. Razão e emoção. 4. ed. São Paulo: Edusp, 2008, p. I03-I04.

4 Milton Santos, em A natureza do espaço. Técnica e tempo. Razão e emoção 4, op.cit., estabelece uma analogia entre o palimpsesto (escritas sobrepostas que é frequente encontrar nos manuscritos sobre pergaminho) e a paisagem, sob inspiração dos criadores da geografia retrospectiva, revelando-se leitor de Marc Bloch (Apologie pour l'histoire ou métier d'historien,I974, p. 49-50) e Fernand Braudel (La Mediterranée et le monde mediterranéen à l'époque de Philippe II, I982, bem como Civilisation matérielle. Economie et capitalisme, XVe-XVIIIe siècle, I979, especialmente Tom. III).

5 BRAUDEL, F. La Mediterranée et le monde mediterranéen à l'époque de Philippe II. (Ia. ed., I949). 5. ed. Paris: Armand Collin, I982, 2 v.; BRAUDEL, F. Civilisation matérielle. Economie et capitalisme, XVe-XVIIIe siècle. Paris: Armand Collin, I979, 3 v. 
processo social, cumprindo-nos retomar a história que esses fragmentos de diferentes idades representam tal como a sociedade a escreveu de momento em momento.

O desafio no presente artigo é ensaiar uma metodologia capaz de desvelar as camadas desse palimpsesto, tateando alguns vestígios e imaginando as lógicas que presidiram a sua produção e apropriação. Nesse sentido, aproximamo-nos do que os historiadores da cultura material chamam de "arqueologia da paisagem", inventando uma metodologia com evidentes paralelos com o que o grupo de Bernard Gauthiez ${ }^{7}$ vem desenvolvendo para o caso de Lyon, com o qual trocamos experiências no âmbito do Projeto USP-Cofecub, parceria entre a Universidade de São Paulo e o Comité Français d' Evaluation de la Coopération Universitaire avec le Brésil. Essa linha de investigação em história urbana tem matriz em estudos anteriores, como os de Luigi Salerno, Luigi Spezzaferro e Manfredo Tafuri ${ }^{8}$ e de François Boudon, André Chastel, Hèléne Couzy e Françoise Hamon?.

Para o cumprimento dos nossos objetivos, entrecruzamos fontes seriais diacrônicas e sincrônicas, tais como impostos prediais ${ }^{\mathrm{IO}}$, permissões de construção $0^{\mathrm{II}}$, anuários estatístico ${ }^{\mathrm{I2}}$, propagandas de jornais ${ }^{\mathrm{I3}}$, legislação, dados demográficos e iconográficos, georreferenciados e espacializados nas plantas de São Paulo de I844-I847 e no Mapa Digital da Cidade (2004-2006). Nosso desejo é pôr luz no bota-abaixo que transformou a cidade num verdadeiro canteiro de obras no âmbito de um aquecido mercado imobiliário rentista motivador do investimento na transformação material da cidade.

A transformação da cidade do ponto de vista do seu processo ainda permanece

6 SCHLERETH, T. The city as artifact. In: . Cultural history er material culture: everyday life, landscapes, museums. Charlottesville: University Press of Virginia, I992, p. I83-I93.

7 GAUTHIEZ, B. \& ZELLER, O. Lyons, the spatial analysis of a city in the I7th and I8th centuries. Locating and crossing data in a GIS built from written sources. In: RAU, S. \& SCHÖNHERR. E. (Ed.). Mapping spatial relations, their perceptions and dynamics, lecture notes in geoinformation and cartography. Switzerland: Springer International Publishing, 20I4.

8 SALERNO, L.; SPEZZAFERRO, L.; TAFURI, M. Via Giulia: una utopia urbanística del 500. Roma: Casa Editrice Stabilimento Aristide Staderini SPA, I973.

9 BOUDON, F. et al. Système de l'architecture urbaine. Le quartier des Halles a Paris. Paris: Éditions du CNRS, I977. $2 \mathrm{v}$.

Io Impostos Prediais (Décimas Urbanas), localizados no Arquivo do Estado de São Paulo, datados de I809 e I829, I876, bem como publicados no Correio Paulistano em I886 e I9I4.

II Nossa pesquisa se vale do legado de projeto em políticas públicas (Fapesp, 2006-20I0), no qual coordenamos, junto com Nestor Goulart Reis, a informatização de parte dos desenhos arquitetônicos da Série Obras Particulares do Arquivo Histórico de São Paulo (I906-I9I4), cujos resultados estão na internet (www.projetosirca. com.br) e muito facilitam nossa empreitada atual. Dos 70 mil referentes ao período I906-I920, informatizamos 30 mil, correspondentes à cidade oficial ou àquela que passou pelo crivo da prefeitura no período.

I2 Almanaques (I857, I884 e I890) localizados na Fundação Biblioteca Nacional, Rio de Janeiro. São Anuários Estatísticos que listam os nomes e respectivos endereços dos principais negócios realizados na cidade.

I3 Jornal O Estado de S. Paulo. 
inexplorada pela historiografia. Com raras exceções ${ }^{\mathrm{I} 4}$, a imagem que temos é aquela cristalizada nos cartões-postais com os resultados finais alcançados, sem que percebamos os ritmos, os percalços, os estímulos e os atores envolvidos.

O recuo ao início do século XIX é estratégico para focalizar as inflexões no mercado imobiliário rentista, que ensejou tais mudanças. O papel da iniciativa privada na produção material dos imóveis é nossa principal preocupação, acrescida de questões como as continuidades e rupturas no perfil dos proprietários dos imóveis, no perfil dos usuários e usos, na natureza dos programas edilícios implantados, na natureza das construções. Preocupa-nos perceber o quanto os imóveis individualmente colaboraram no desenho de uma nova tessitura urbana. Advogamos a tese de que boa parte das renovações foi obra da iniciativa privada, orquestrada e induzida pelo poder público por meio de pormenorizada legislação e alguns planos urbanísticos. Neste artigo ensaiamos assim os primeiros passos de uma metodologia de investigação em história da urbanização que tem como foco o processo de produção social da cidade na escala do edifício, das ações individuais, da arquitetura comum no âmbito de um pragmático mercado imobiliário rentista.

Espacializar os dados na escala do edifício não é tarefa fácil, implica risco de imprecisão, mas permite aquilatar aspectos invisíveis do processo. Permite também: entrever a sociotopografia ${ }^{\text {I5 }}$ urbana e as hierarquias entre espaços mais e menos valorizados; imaginar as motivações que justificaram o investimento na construção, reforma, demolição e reconstrução de prédios para renda de aluguel; e constatar que até a Lei do Inquilinato, em I942, boa parte dos habitantes das cidades brasileiras morava e trabalhava em imóveis de aluguel, o que tornava atraente para os segmentos sociais detentores de certo montante de capital imobilizar recursos na edificação de casas, lojas, armazéns e prédios de uso misto com fins rentistas.

Notamos que, desde o período colonial, 50\% do tecido urbano da cidade de São Paulo era composto de imóveis de aluguel e que, até a década de I940, essa prática de investimento se manteve constante, nos legando um significativo conjunto de prédios no centro histórico ainda hoje pertencentes inteiramente a determinadas famílias, resquício de uma época em que a organização condominial engatinhava.

Outro aspecto interessante observado é o perfil social dos investidores no centro da cidade, em geral, membros da velha oligarquia. O Estado, por meio de iniciativas estrategicamente posicionadas, induziu ou consolidou o desenvolvimento em determinadas direções, no entanto, os recursos públicos imobilizados nas operações urbanísticas foram ínfimos quando comparados ao capital privado. A nosso ver, a terceirização à iniciativa empresarial foi a opção adotada para atender às demandas da explosão demográfica, que exigiu novos espaços num curto período de tempo, garantindo lucros seguros aos investidores. Mas se pouco investiu financeiramente,

I4 BARBUY, H. A cidade-exposição. Comércio e cosmopolitismo em São Paulo, I860-I9I4. São Paulo: Edusp, 2006; BARBUY, H. Seguindo Militão pelas ruas da cidade. In: FERNANDES JR., Rubens; BARBUY, Heloisa; FREHSE, Fraya. Militão Augusto de Azevedo. São Paulo: Cosac Naify, 20I2; LÉFÈVRE, J. E. De beco a avenida. A história da Rua S. Luiz. São Paulo: Edusp, 2006.

I5 Sobre o conceito de sociotopografia consultar: LE GOFF, J. O a pogeu da cidade medieval. São Paulo: Martins Fontes, I992, p. I45-I92. 
o Estado funcionou como indutor e orquestrador do processo, alocando equipamentos públicos (teatro, mercado, sede dos correios e telégrafos, escolas, edifícios administrativos) em determinados lugares, encabeçando operações de abertura de praças modernas (Antônio Prado e Patriarca), remodelando paisagisticamente as áreas de várzea (parques Anhangabaú e D. Pedro II) e removendo das áreas centrais população, edificações (Igreja do Rosário dos Pretos e Misericórdia) e atividades (fábricas, comércio de molhados e pequenos serviços) indesejadas por meio de uma legislação urbanística que desenhou uma clara geografia dos usos com consequente valorização e desvalorização fundiária.

Nesse sentido, essa linha de investigação permite entrever a eficácia ou não de certos instrumentos e mecanismos de indução, orquestração e controle do processo de urbanização por parte do poder público, garantindo feições mais e menos homogêneas ao conjunto, cerceando ou estimulando as ações individuais em prol de certo ideal de cidade resumido no slogan "Embelezamento e melhoramentos urbanos". Nesse universo vemos frequentemente se irmanarem interesses públicos e privados, muitas vezes confundindo-se os primeiros com os últimos ${ }^{\mathrm{It}}$.

Por fim, estudos dessa natureza permitem ainda entrever o processo de transformação dos espaços, rua a rua, lote a lote, imaginando os imóveis em obras. Esse retrato do processo no seu fazer cotidiano escapa à historiografia tradicional, mais atenta aos grandes planos urbanísticos, aos profissionais do urbanismo, aos grandes engenheiros e arquitetos, à legislação higienista em abstrato, aos cenários eternizados nos cartões postais. Com foco nos pormenores, buscamos reconstituir a fábrica urbana em transformação, questionando as lógicas que entreteciam interesses públicos e privados. Trata-se de um dos períodos mais interessantes da história de São Paulo, de transformações intensas não por acaso eternizadas por Benedito Lima de Toledo ${ }^{\mathrm{I}}$ na metáfora "três cidades em um século".

I6 Sobre a interdependência entre interesses públicos e privados consultar: ROLNIK, Raquel. A cidade e a lei. 3. ed. São Paulo: Studio Nobel/Fapesp, I998; CAMPOS, C. M. Os rumos da cidade - urbanismo e modernização em São Paulo. São Paulo: Senac, 2002.

I7 TOLEDO, B. L. de. São Paulo: três cidades em um século. 2. ed. São Paulo: Duas Cidades, I983. 


\section{Cartografias Regressivas}

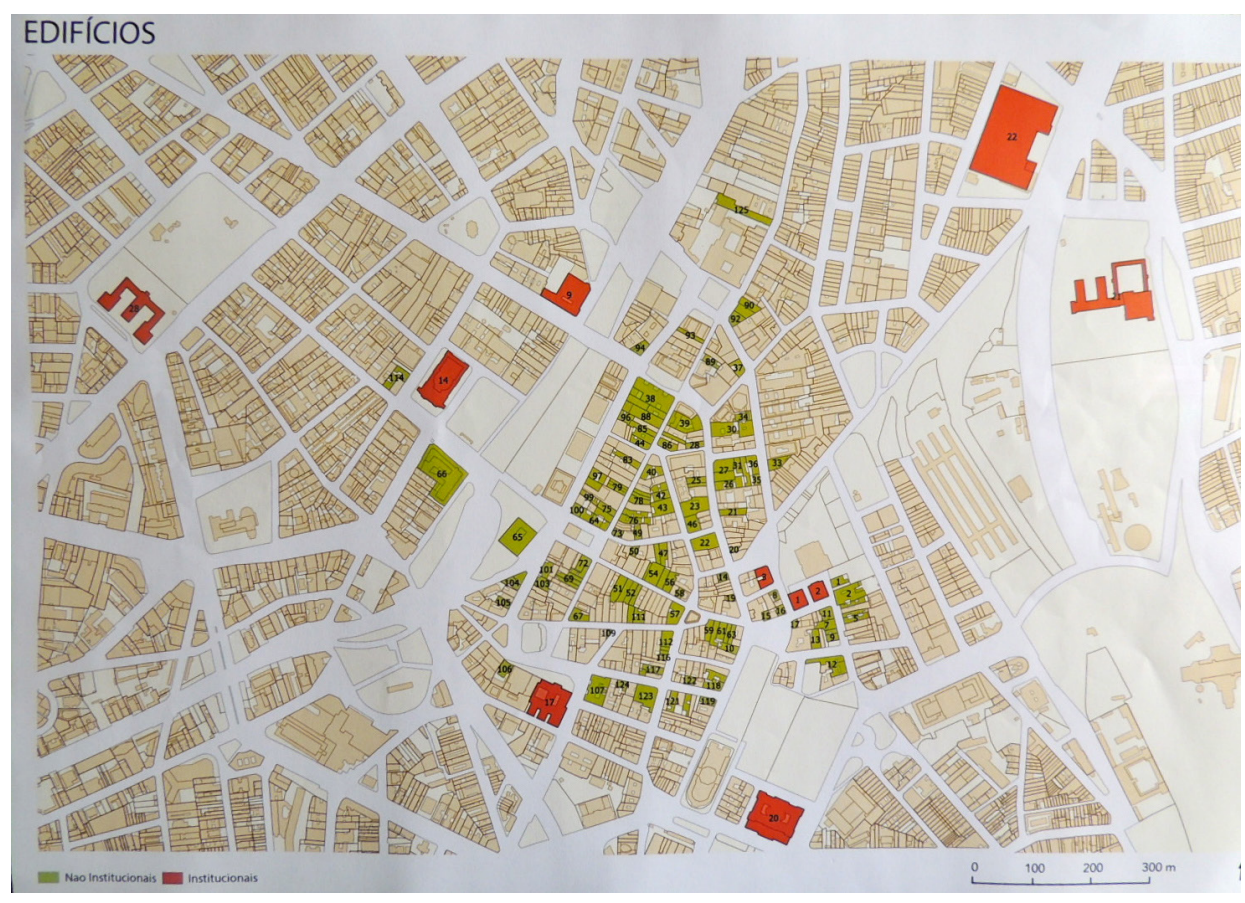

Figura I - Amostragem dos I20 imóveis eleitos para estudo. Espacialização dos dados por meio do Quantum GIS no Mapa Digital da Cidade de São Paulo de 2004-2006. Prefeitura do Município de São Paulo.Inventário realizado com auxílio dos alunos da disciplina AUH 238 Estudos de Urbanização, 20I5, bem como dos bolsistas de iniciação científica Marcos Calixto Rios (Fundação de Amparo à Pesquisa do Estado de São Paulo - Fapesp) e Marina Gonçalves Marques (Conselho Nacional de Desenvolvimento Científico e Tecnológico - CNPq).

Em vermelho, edifícios institucionais, todos projetados pelo Escritório F. P. Ramos de Azevedo, Severo \& Villares:

I- Secretaria da Fazenda (I886-I89I)

2- Secretaria da Agricultura (I892-I896)

3- Antigo edifício da Bolsa de Mercadorias (I933-I937)

9- Correios e Telégrafos (I920-I922)

I4- Teatro Municipal (I903-I9II)

I7- Faculdade de Direito (I933)

20- Tribunal de Justiça (I920-I933)

2I- Palácio das Indústrias (I9II-I924)

22- Mercado Municipal (I922-I933)

28- Escola Normal (I892-I894) 
Em verde, edifícios para particulares:

I- Casa n. I - Major Antonio Benedito da Silva - I880 - 3 andares - tijolo

2- Solar da Marquesa - Felício Pinto de Mendonça e Castro - séc. XVIII - 2 andares - taipa de pilão e tijolo

3- Ordem do Carmo - séc. XIX - 3 andares - tijolo

4- Prédio da Santa Casa de Misericórdia - Cia. Iniciadora Predial/Ricardo Severo I9I3 -3 andares - tijolo

5- Antônio de Queiroz Telles - Jorge Krug - I9I3 - 5 andares - concreto e tijolo

6- ? - Rangel Christoffel e Cia. Engenheiros Construtores - séc. XX - concreto e tijolo 7- Sociedade de Medicina e Cirurgia - I895 - tijolo

8- ? - ? - séc. XX - 8 andares - concreto e tijolo

9- Álvaro de Macedo Guimarães - I895 - 2 andares - tijolo

Io- ? - ? - séc. XX - concreto e tijolo

II- ? - Giulio Micheli - I896 - 3 andares - tijolo

I2- Palacete Carmo - Cúria Metropolitana - séc. XX - 7 andares - concreto e tijolo I3- ? - Jorge Muller \& Irmãos - I909 - 3 andares - concreto e tijolo

I4- Edifício Azevedo Villares - Arnaldo Dumont Villares e Eugenia Lacaze - Ramos de Azevedo, Severo \& Villares - I945 - I8 andares - concreto e tijolo (demolição de prédio construído para Domingos Paiva Azevedo em I905 por Samuel das Neves) I6- J. C. Costa - Ao Grande Oriente (I889) - [Ramos de Azevedo] - I888 - 2 andares tijolo e taipa de mão

I7- Edifício Rolim - Família Prado Rolim - Escriptório Technico Pujol Junior, F. Rei ann, T. Carvalho \& D. Tacini - I928 - I4 andares - concreto e tijolo

I8- Prédio Piratininga - I929- 9 andares - concreto e tijolo

I9- Luiz de Vasconcellos - Giulio Micheli - I906 - concreto e tijolo 20- ? - Vauthier - séc. XX - 3 andares

2I- Banco Português do Brasil - F. P. Ramos de Azevedo \& Cia. - I9I9 - 5 andares concreto e tijolo (demolição do Banco di Napoli construído para o comendador João Brícola por Samuel das Neves em I9I2)

22- London \& Brazilian Bank - F. P. Ramos de Azevedo \& Cia. - I920 - 3 andares

23- Banco Francês-Italiano - Giulio Micheli - I9I8 - 3 andares - concreto e tijolo (demolição de imóvel construído por Carlos Ekman para o conde Álvares Penteado em I9II)

24- Jacob Levy - Samuel das Neves - I9I2 - 6 andares

25- José K. Fakhoury - F. P. Ramos de Azevedo \& Cia. - I9I3 - 5 andares - concreto e tijolo

26- ? - Giulio Micheli - I9I5 - 3 andares - tijolos

27- Brasilianische Bank fur Deutschland - Guilherme Krug \& Filho - [I897] - 3 andares - concreto e tijolo

28- ? - Luiz de Vasconcellos - Giulio Micheli - I9II - 3 andares - concreto e tijolo

30- Banco Comercial de São Paulo - F. P. Ramos de Azevedo \& Cia. - I924 - Io andares - concreto e tijolo (antiga Galeria de Cristal construída por Max Hehl para Cristiano Webendoerfer em I900)

3I- ? - ? - séc. XX - 6 andares - concreto e tijolo

32- Tacito de Toledo Lara - séc. XX - 7 andares - concreto e tijolo 
33- Casa Ramos de Azevedo - Ramos de Azevedo - F. P. Ramos de Azevedo \& Cia. (Ia sede do escritório) - I922 - 9 andares - concreto e tijolo - no térreo, Casa Ernesto de Castro (loja de importação de materiais de construção, pertencente ao genro de Ramos de Azevedo)

34- Anexo Edifício Altino Arantes - Banco do Estado de São Paulo - Plinio Botelho do Amaral e Camargo \& Mesquita - séc. XX - I7 andares - concreto tijolo

35- ? - ? - séc. XX - I6 andares - concreto e tijolo

36- Casa Palmares - condessa Álvares Penteado - F. P. Ramos de Azevedo \& Cia. - I922 -8 andares - concreto e tijolo

38- Edifício Martinelli - Giuseppe Martinelli/William Filinger/Robert e Raul Lacombe - I929 - 24 andares - concreto e tijolo

39- Banco de São Paulo - Álvaro Botelho - I935 - I3 andares - concreto e tijolo

40- Palacete Crespi (atual Edifício York) - Rodolfo Crespi - Giovanni Battista Bianchi - séc. XX - 9 andares - concreto e tijolo

4I- Banco Ítalo-Belga - Edifício Malvina Chamas Curi - F. P. Ramos de Azevedo \& Cia. - I9IO [I9II] -5 andares - tijolo

42- Palacete Lara - Siciliano e Silva Engenheiros \& Construtores - séc. XX - 6 andares - concreto e tijolo

43- British Bank of South America Limited - Scott Urner - I926 - 4 andares

44- Edifício Álvares Penteado - F. P. Ramos de Azevedo \& Cia. - I938-I939 - concreto e tijolo.

46- Banco do Brasil - Escriptorio Technico Pujol Junior, F. Reimann, T. Carvalho \& D. Tacini - séc. XX - concreto e tijolo

47- ? - L. Serva \& Cia. - I9I7 - 5 andares - concreto e tijolo

48- ? - Walter Brune - séc. XX - 3 andares

49- Edifício Gaia - José Maria Raimundo da Costa - Eduardo Mendes Gonçalves I9IO -3 andares - tijolo

50- ?- ? - I903 - 3 andares - tijolo

5I- Cine Alhambra - Manuel Pereira Guimarães - José Maria da Silva Neves - I927-2 andares

52- ? - Manuel Pereira Guimarães - Carlos Ekman - I9I8 - 2 andares - tijolo

53- ? - Germaine Lucie Burchard - Vicente Branco - I920 - tijolo

54- Casa Alemã - J. Heydenreich e Jose Vollsach - Carlos Ekman - I9Io - 5 andares - concreto e tijolo

55- ? - Armando Álvares Penteado - I9I9 - 3 andares - tijolo e taipa

56- ? - Ordem Terceira do Carmo - Max Hehl - I909- 3 andares

56-? Santa Casa de Misericórdia - Giulio Micheli - I907- 3 andares - concreto e tijolo

57- Palacete Thereza de Toledo Lara-Antonio Toledo Lara - Augusto Fried - I908 - 3 andares - tijolo

58- ? - Int. Cia. L'Union de Seguros - I9I8 - 3 andares

59- Farmácia Amarante - Joze Estanislau do Amaral - Oscar Kleinschmidt - I893-3 andares

60- ? - Joze Fernandes Pinto - I895 - 3 andares

6I- Edifício Guinle e Cia. - Guinle e Cia. - Hypolito Pujol Junior - I9I2 - 8 andares - 
concreto e tijolo (em I895 ali fora construído prédio a cargo de José Fernandes Pinto, simultaneamente ao anterior)

63- Edifício Lutétia - Família Álvares Penteado - F. P. Ramos de Azevedo \& Cia. - I9I4 -8 andares - concreto e tijolo

64- Edifício Matarazzo - Francisco Matarazzo - Ramos de Azevedo, Severo \& Villares - I939- 8 andares - concreto e tijolo

66- Edifício Alexandre Mackenzie - The São Paulo Tramway Light and Power Ramos de Azevedo, Severo \& Villares - I929 - 8 andares - concreto e tijolo

67- Edifício Brigadeiro Luiz Antonio - Paula de Souza Queiroz - Max Hehl - I909-3 andares - tijolo

68- ? - Francisco Rivera - I908 - 2 andares - tijolo

69- ? - Francisco Rivera - I908 - 2 andares - tijolo

70- ? - Marina Branco de Melo M. Aires de Souza - Adriano Correia de Andrade I890 -3 andares - tijolo

7I- ? - Antonio de Toledo Lara - Augusto Fried - I980 - 3 andares

72- Edifício Notaroberto - Ana Francisca da Silva Marques - Francisco Nottaroberto - I908 -3 andares - concreto e tijolo

73- Casa Fretin - Henrique Sertorio - Ricardo Severo - I886 - 6 andares - concreto e tijolo

74- Palacete Elias Chaves - 3 andares - taipa e pilão

75- ? - Antonio de Toledo Lara - Augusto Fried - I909 - 3 andares - concreto e tijolo 76- ? - Henrique Sertorio - Ricardo Severo - I9I3 - 6 andares

77- Ana Maria Nogueira - Joze Paula Leite de Barros - Ricardo Severo - I9I3 - 5 andares - concreto e tijolo

78- ? - Cecilia de Almeida Prado Amaral e outros - séc. XX - 2 andares - concreto e tijolo

79- Cine São Bento - Empresa Bunge - I927 - I andar - tijolo

80- ? - Matheus Haussler - I887 - 2 andares - tijolo

8I- ? - Manuel dos Reis Pedro da Rocha - I894 - 2 andares - tijolo

82- Loja do Japão - Manuel Garcia da Silva - Manuel dos Reis Pedro da Rocha - I894 -2 andares - tijolo

88- Edifício Sant'Ana - Stella Penteado - Siciliano e Silva Engenheiros \& Construtores - séc. XX - 9 andares - concreto e tijolo

89- ? - Antonio de Paula Assis - J. J. Ferreira - I9O3 - 3 andares - tijolo

90-? - ? - séc. XX - 2 andares - tijolo

9I- ? - Morisim - I887- 2 andares - tijolo

92- Hotel d'Oeste - José Zucchi e irmão - Rossi \& Brenni - I9OI - 2 andares - tijolo

93- Edifício Maurice Levy - I9I4 - 4 andares - concreto e tijolo

94- Edifício Cidade de São Paulo - Daniel Dhelomme - Ramos e Azevedo, Severo \& Villares - I923 - 7 andares - concreto e tijolo

95- Edifício Stella Penteado - Stella Penteado - Siciliano e Silva Engenheiros \& Construtores - I925- 8 andares - concreto e tijolo

96- ? - Antonio Carlos de Arruda Botelho - Samuel das Neves - I9I3 - 4 andares concreto e tijolo 
97- Edifício Sampaio Moreira - Joze Sampaio Moreira - Samuel das Neves - I924 - I4 andares - concreto e tijolo

98- ?- ? - séc. XX - 6 andares - concreto e tijolo

99- ? - Antonio de Toledo Lara - Albuquerque \& Longo Engenheiros Arquitetos Civis - I924- 7 andares - concreto e tijolo

Ioo- Edifício Patriarca - Siciliano e Silva Engenheiros \& Construtores - I924 - 9 andares - concreto e tijolo

IOI- Edifício Liberty Paulista - Cia. Paulista de Seguros - Ramos de Azevedo, Severo \& Villares - I94I - 24 andares - concreto e tijolo

I02- Palácio Médici (Casa Médici) - Luiz Medici - Samuel das Neves - I9I2 - 7 andares - concreto e tijolo

I03- Edifício Britânia - Arnaldo Dumont Villares - Ramos de Azevedo, Severo \& Villares (2a sede do escritório) - I943 - 2I andares - concreto e tijolo

Io4- Edifício São Joaquim - Henrique de Souza Queiros - Henri Paul Pierre Sajous (Severo \& Villares) - séc. XX - concreto e tijolo

I05- ? - Antonio Alfredo Vaz Serquinho - Giulio Micheli - I9I2 - 4 andares - tijolo

Io6- Edifício Frei Sant’ Anna Galvão - Ordem Terceira de São Francisco - I94I - 8 andares - concreto e tijolo

I07- Escola de Comércio Álvares Penteado - Antonio Alvares Penteado - Carlos Ekman - I907- 2 andares - tijolo

I09-? - ?- séc. XX - 8 andares - concreto e tijolo

IIO- ? - ? - séc. XX - 2 andares - tabique

III- ? - Cia. Americana de Seguros - Rangel Christoffel e Cia Engenheiros Construtores - I924- 8 andares - concreto e tijolo

II2- ? - Ribeiro da Silva - I908 - 3 andares - concreto e tijolo

II4- Edifício Glória - Samuel Ribeiro - Albuquerque \& Longo Engenheiros Arquitetos e Civis - I928 - II andares - concreto e tijolo

II5- ? - ? - I92I - IO andares - concreto e tijolo

II6- Chapelaria Paulista - Humberto Zucchi - I9I4 - 2 andares - concreto e tijolo

II7- Edifício Henrique Lindenberg - Henrique Lindenberg - séc. XX - 5 andares concreto e tijolo

II8- Palacete São Paulo - Felicio de Campos Cintra - Hildebrando Cintra - Arquitetos Albert \& Wedwe e Hugo Haroni - I924 - 7 andares - concreto e tijolo

II9- Edifício Antônio Gazeau - Augusto Gazeau - I9Io - 7 andares - concreto e tijolo I2O- ? - ? - Siciliano e Silva Engenheiros \& Construtores - I932 - 9 andares - concreto e tijolo

I2I- Palacete Gonzaga - Joze Gonzaga Franco Filho - Siciliano e Silva Engenheiros \& Construtores - I925- 8 andares - concreto e tijolo

I22- ? - Arthur Guimaraes - Francisco Salles Malta Junior - I922 - 3 andares concreto e tijolo

I23- Edifício Casa das Arcadas - Armando Alvares Penteado - Siciliano e Silva Engenheiros \& Construtores - I929 - 8 andares - concreto e tijolo

I24- Palacete Chavantes - João Batista Mello de Peixoto - Alexandre Ribeiro Marcondes Machado (Juo Bananere) - I926 - Io andares - concreto e tijolo I25- Casa da Boia - Rizkallah Jorge Tahan - I9I9 - 2 andares - tijolo 
Elegemos as I20 edificações mais representativas das diversas etapas, cujas fachadas não estão hoje muito adulteradas. Para contextualizar o universo que ensejou a produção desse conjunto de edificações, convém apresentar alguns dados demográficos com outros referentes ao boom imobiliário para dar a medida do aumento das demandas por novas edificações e questionar se as ofertas responderam à crescente procura. Só para se ter uma ideia da intensidade do processo, em I808, São Paulo tinha 7 mil habitantes vivendo no perímetro urbano. Em I872 a cifra subiu para 26.040 pessoas e, em função da economia cafeeira no oeste paulista e da imigração, a população explodiu para 47.697 em I886, $64.934 \mathrm{em}$ I890, quadruplicando na década seguinte e atingindo, em I905, 300.569 habitantes e, em I9I3, 460.26I cidadãos. Desde então, a população não parou mais de crescer, duplicando, em I920, para 579.000 habitantes, em I930, totalizando 900.000 habitantes e, em I940, I.326.26I indivíduos.

A esses dados somam-se o número de prédios registrados na Planta geral da cidade de São Paulo de I9I4: I840 - I.843 edificações; I875 - 2.992; I886 - 7.0I2; I895 - I8.505; I900 - 2I.656; I905 - 25.976; I9IO - 32.9I4; I9I2 - 39.797; I9I3 - 43.940. Comparativamente à explosão demográfica, a oferta de imóveis parece inferior à demanda. Por exemplo, se dividirmos a população de I9I3 pelo número de prédios disponíveis, verificamos que cada unidade deveria abrigar io pessoas, o que certamente não ocorria. Ou seja, a oferta aquém da procura condiciona o aumento dos preços dos aluguéis e torna cada vez mais rentável o investimento no mercado imobiliário. Por outro lado, o aumento dos aluguéis certamente gerou um conjunto de edificações informais que não passaram pelo crivo da burocracia municipal, uma "cidade não oficial" ainda carente de ser quantificada. A legenda da Planta de I9I4 traz ainda outra informação relevante:

[...] o rendimento annual desses 43.940 prédios existentes em I9I3 estava oficialmente calculado em 75.419:002\$000 (setenta e cinco mil, quatrocentos e dezenove contos e dois mil réis). O valor venal desses podia ser estimado em 754.I90:020\$000 (setecentos e cincoenta e quatro mil, cento e noventa contos e vinte mil réis) papel brasileiro"ז8.

Esses dados são importantes para mensurar o montante investido no mercado imobiliário, permitindo aquilatar a fortuna de certos investidores comparativamente ao conjunto, tais como Germaine Burchard (54:802\$660 réis), o conde de Toledo Lara (42:410\$400 réis), o conde de Prates (34:733\$400 réis), Manoel Garcia da Silva (30:03I\$400 réis) e o conde Álvares Penteado (25:603\$840 réis), os maiores proprietários de imóveis no perímetro central segundo o Imposto Predial de I9I3-I9I4.

A cidade outrora concentrada na colina histórica espalhou-se em todas as direções como uma colcha de retalhos de investimentos privados, envolvendo o loteamento de chácaras por parte de capitalistas muitas vezes também vinculados ao financiamento e à infraestrutura dos empreendimentos, lucrando muito com isso ${ }^{\text {IT }}$. A

I8 Planta geral da cidade de São Paulo de I9I4.

I9 BRITO, M. A participação da iniciativa privada na produção do espaço urbano. São Paulo I890-I9II. São Paulo: FAU/USP, 2008. 
Planta geral da capital de São Paulo de I897, comparativamente à elaborada pela Cia. Cantareira em I88I, revela que a mancha urbana mais do que triplicou em apenas dezesseis anos. Concomitantemente verificou-se a surpreendente metamorfose da paisagem do perímetro central ${ }^{20}$ definido em I9I6, destinado ao comércio e aos serviços especializados, ensejando interesse por parte desses mesmos "empresários e capitalistas" na construção de imóveis de uso misto para renda de aluguel, muitas vezes logo alteados ou simplesmente demolidos para dar lugar a outros mais verticais, num complexo jogo de substituições somente justificado no quadro do aumento de demandas em curso.

Raras são as fotos que demonstram o canteiro de obras em que a cidade se transformou entre I900 e I940. Em meio à introdução das linhas de bonde (I900), iluminação elétrica (I900) e ligações de esgoto e água encanada (a partir de I906-I908 na área central), quadra a quadra, lote a lote, o coração da metrópole do café foi totalmente reescrito, sobrando na paisagem atual uns poucos exemplares de taipa de pilão ou de taipa de mão do século XVIII e primeiras décadas do XIX, tais como o Solar da Marquesa dos Santos ${ }^{21}$, o Palacete Elias Chaves ${ }^{22}$, a antiga Casa Ao Grande Oriente na Praça da $\mathrm{Sé}^{23}$ e algumas poucas igrejas.

\section{O RETRATO DA CIDADE PRETÉRITA NOS IMPOSTOS PREDIAIS}

A interpretação da Décima Urbana de $1809^{24}$ possibilitou um retrato da tessitura da cidade antes da sua primeira transformação, lançando luz nos atores sociais detentores dos imóveis. Espécie de recenseamento por escrito, o Imposto Predial revelou uma cidade constrangida na colina entre os rios Tamanduateí e Anhangabaú, contendo apenas I.28I imóveis ${ }^{25}$, predominantemente térreos e residenciais: $86 \%$ deles eram casas comuns de taipa de pilão (I.047), em meio a apenas I6I sobrados (I3\%). No que diz respeito aos usos, 86\% (IO5I) eram residências, $2 \%$ (26) lojas e IO\%

20 GLEZER, R. São Paulo, cem anos de perímetro urbano. História (São Paulo), v. I3, p. I55-I66, I994.

2I Atual Museu da Cidade, sito à rua Roberto Simonsen.

22 Sito na confluência da Rua de São Bento com a Praça do Patriarca.

23 Supostamente a segunda obra de Ramos de Azevedo na cidade, situa-se contígua à Secretaria da Fazenda (I886). Teve sua fachada desapropriada, recortada, encamisada com tijolos e remodelada sob padrões neoclassicistas em I888, devido ao alargamento das ruas adjacentes ao Pátio do Colégio, mantendo suas paredes interiores de taipa e mão sobre barrotes e assoalho de madeira. Exemplar de uma cidade de transição que acreditávamos desaparecida, o edifício sofreu reforma (velada sob o nome de restauro) e descaracterização para abrigar a sede de um banco em 20I5-20I6, o que demontra insensibilidade para com a história e impotência dos orgãos de preservação para conter a especulação imobiliária.

24 BUENO, B. P. S. Tecido urbano e mercado imobiliário em São Paulo; metodologia de estudo com base na Décima Urbana de 1809. Anais do Museu Paulista: História e Cultura Material, n.I3, p. 49-99, 2005.

25 Em I808 tínhamos 7.000 habitantes residindo em I.28I prédios, numa média de ocupação de 5,4 indivíduos por casa. Um século mais tarde, em I9I3, são 460.26I cidadãos residindo em 43.940 prédios, numa média de Io,47 por imóvel. 
(I32) imóveis de uso misto. Constatamos que 50\% (638) das edificações destinavam-se à renda de aluguel.

A Décima Urbana de I809 permitiu entrever que, na aparente homogeneidade do conjunto, a São Paulo colonial apresentava espaços especializados e espacializava o degradé social então vigente, contendo áreas mais e menos valorizadas. As zonas mais caras eram aquelas junto dos largos da Sé, do Pátio do Colégio e ruas de uso misto a eles contíguas, concentrando o comércio e os sobrados da cidade.

Já as casas térreas, predominantemente de porta e janela, ficavam na extremidade e junto das várzeas do Tamanduateí e Anhangabaú. Lote a lote, o estudo permitiu falar de mercado imobiliário em tempos recuados, mostrar as faces dos principais proprietários dos imóveis - em geral negociantes -, algo a que a historiografia vinha dando pouca ênfase.

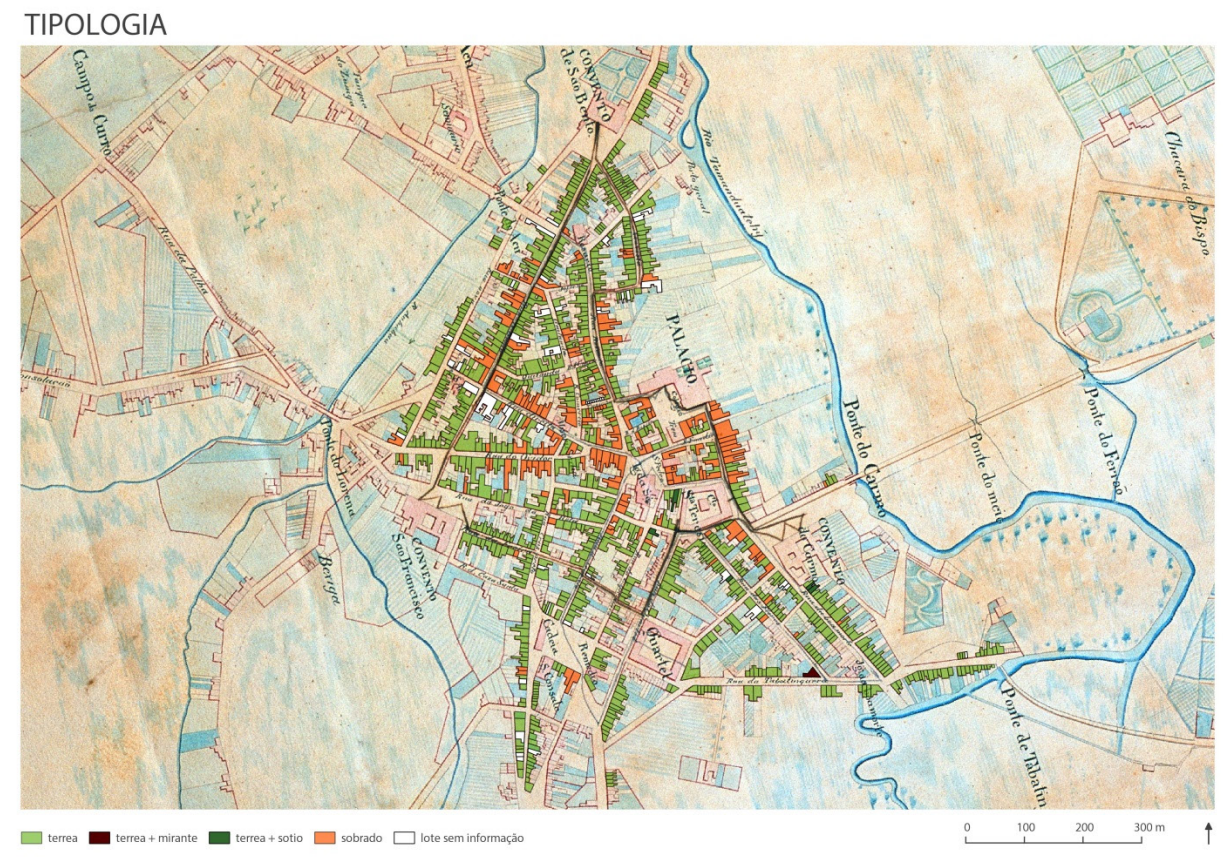

Figura 2 - Tipologia dos imóveis em I809: em verde, 86\% de casas comuns de taipa de pilão (I.047) e, em vermelho, I6I sobrados (I3\%). Dados da Décima Urbana de I809 espacializados por meio do Quantum GIS na Planta da cidade de São Paulo de I844I847 de Carlos Bresser. Original pertencente à Fundação Biblioteca Nacional (BNRJ) 


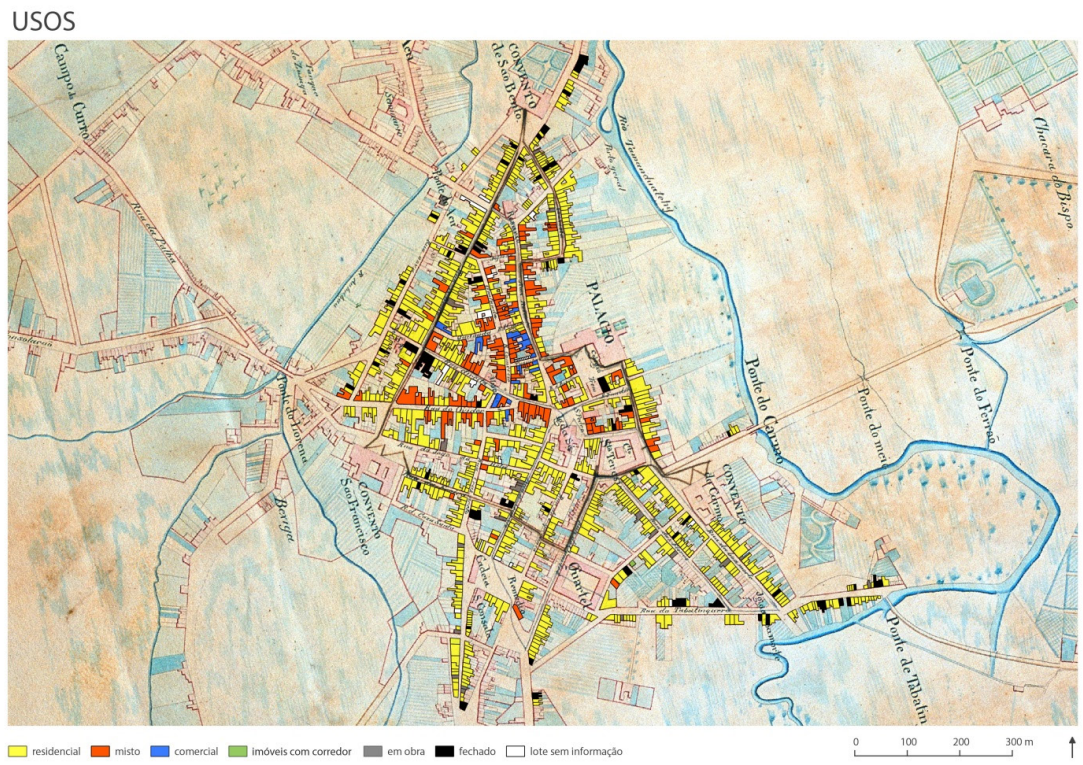

Figura 3-Usos dos imóveis em I809: em amarelo, 86\% (I.05I), residências; em azul, $2 \%$ dos imóveis exclusivamente comerciais (26 lojas); em vermelho, os IO\% (I32 imóveis) de uso misto; em preto, os imóveis fechados. Planta da cidade de São Paulo de I844-I847 de Carlos Bresser. BNRJ.

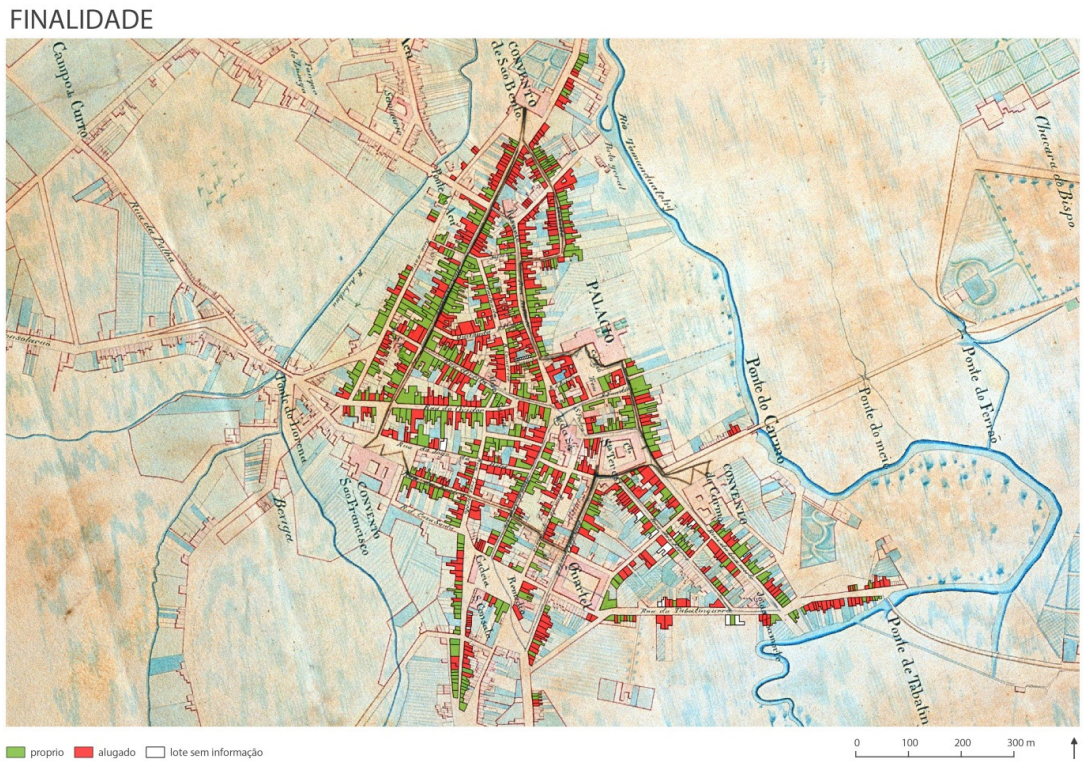

Figura 4- Finalidade dos imóveis em I809: 50\% (638) das edificações destinavamse à renda de aluguel. Em verde, os 50\% destinados a uso próprio e, em vermelho, os 50\% alugados. Planta da cidade de São Paulo de I844-I847 de Carlos Bresser. BNRJ. 


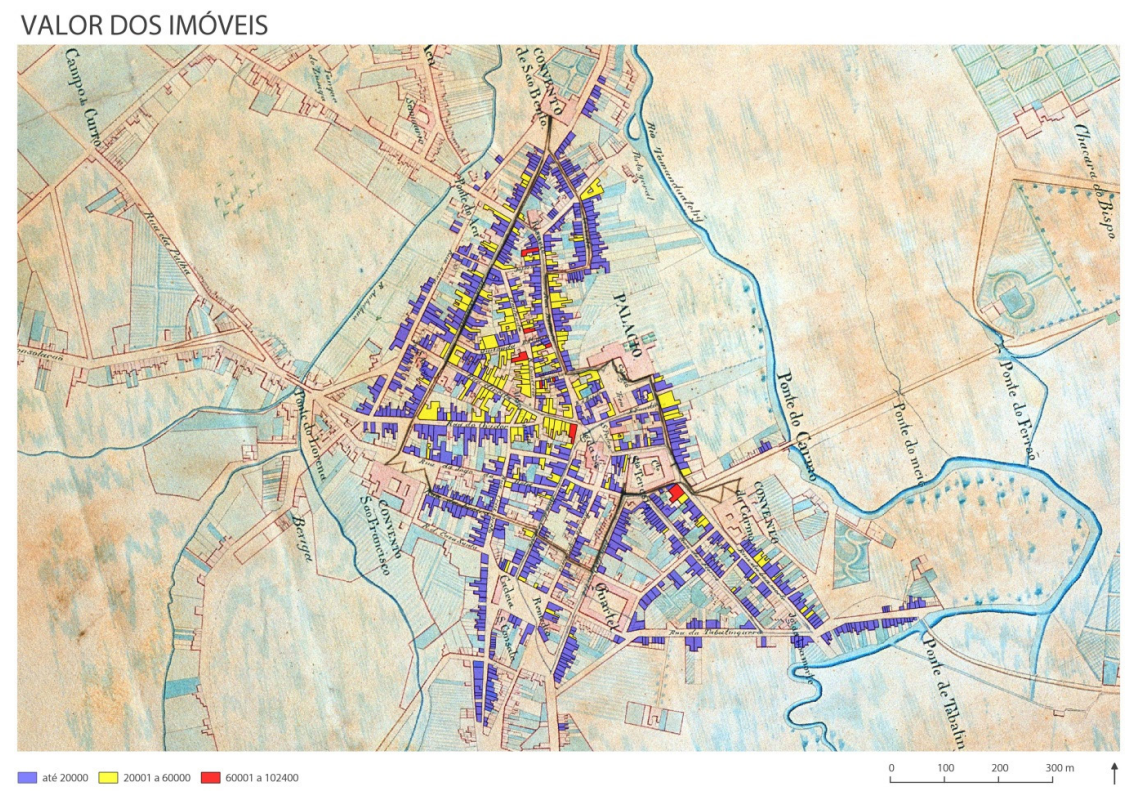

Figura 5 - Valor dos imóveis em I809: as áreas mais valorizadas concentravam sobrados de uso misto, no triângulo formado pelas ruas Direita, Rosário, São Bento, Ouvidor e Comércio. Em vermelho, os sobrados mais caros; em amarelo, os imóveis de uso misto de alto valor, coincidentes com as ruas de comércio; em roxo, os mais baratos, em geral casas térreas. Planta da cidade de São Paulo de I844-I847 de Carlos Bresser. BNRJ.

A Décima Urbana de I809 revelou a concentração de prédios urbanos nas mãos de poucos. Dos 748 proprietários, apenas 24 (3,2\%) detinham cerca de $1 / 4$ (302) dos I.274 imóveis inventariados em I809. Desde o período colonial, era um bom negócio investir em casa de aluguel - I,8\% mais rentável que emprestar dinheiro a juros, implicando bem menos riscos. Os inventários pós-mortem evidenciam imóvel urbano como opção de investimento. Os maiores proprietários de imóveis de aluguel eram as ordens religiosas (em quantidade) e negociantes vinculados ao comércio internacional, além de tropeiros, senhores de engenho de açúcar e negociantes menores vinculados à venda a retalho (de fazendas secas, ferragens etc.). Os maiores detentores de edifícios urbanos eram os coronéis Jozé Arouche de Toledo e Luiz Antônio de Souza (futuro brigadeiro Luiz Antônio, chefe do clã dos Souza Queiroz), além do Mosteiro de São Bento.

A via mais importante da cidade, em I809, era a Rua Direita, que apresentava 45 imóveis: vinte sobrados, dos quais apenas seis exclusivamente residenciais. Predominantemente ocupada por imóveis de uso misto, a rua mais verticalizada de São Paulo sofreu mutações ao longo do século XIX. Doze casas térreas foram transformadas em sobrados e um sobrado convertido no Solar do Barão de Iguape, o que revela que a cidade apresentou dinâmica relativa entre I809 e as décadas de I860-I880, não se mantendo estagnada, sendo os prédios reformados, alteados e alguns fundidos para dar lugar a outros maiores. A dinâmica, no entanto, é 
incomparável à da virada do século XIX para o XX, em que, a cada cinco anos, cerca de 5.000 novas unidades foram construídas.

Peguemos o exemplo da primeira quadra da Rua Direita para dar uma ideia do teor e ritmo das transformações. Esta era basicamente composta de sobrados de uso misto, alguns deles pertencentes a importantes negociantes vinculados ao comércio de tecidos importados do Rio de Janeiro. Os sobrados descritos na Décima Urbana (I809) são os mesmos nas fotos de Militão em I862 e I887.

Entre I894 e I896, nas mãos de outros proprietários, esses imóveis foram demolidos e a quadra completamente remodelada. Por incrível que pareça, os imóveis em "roxo" (construídos simultaneamente em I895 por proprietários diferentes) foram comprados pelos Guinle, donos da Cia. Docas de Santos, que em I9I2-I9I3 não hesitaram em demoli-los apenas dezoito anos depois de construídos. Os belos predinhos edificados em I895 com tijolo e linguagem eclética cederam assim lugar ao primeiro arranha-céu da cidade em concreto armado, com projeto assinado pelo escritório do engenheiro politécnico Hipolito Pujol. A iconografia revela a metamorfose da feição da quadra efetivada em apenas dois anos.

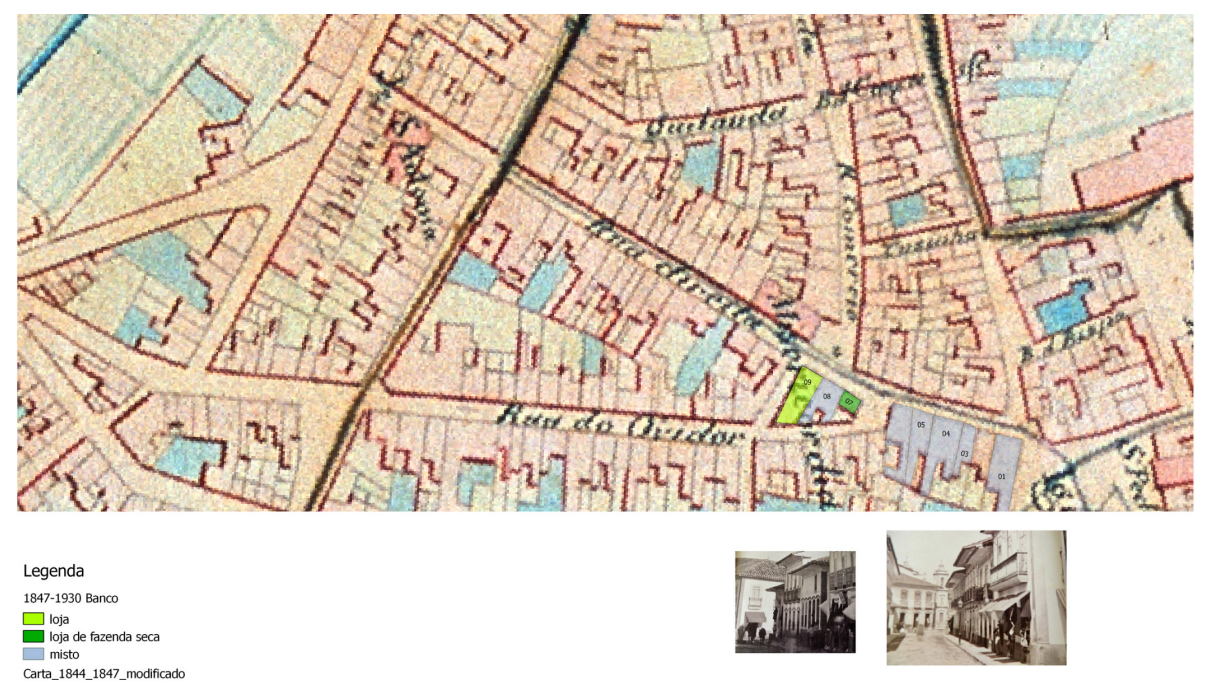

\begin{tabular}{|c|c|c|c|c|c|c|c|c|c|c|c|c|c|}
\hline $\begin{array}{l}\text { RUA } \\
\text { I809 }\end{array}$ & $\begin{array}{l}\text { N } \\
\text { I809 }\end{array}$ & QUADRA & Prop I809 & Perf 1789 & $\begin{array}{l}\text { Escravos } \\
\text { P }\end{array}$ & $\begin{array}{l}\text { AGRE } \\
\text { P }\end{array}$ & INQ I809 & Perf Inq & $\begin{array}{l}\text { Proprio } \\
\text { AL }\end{array}$ & $\begin{array}{l}\text { TiPo } \\
\text { I809 }\end{array}$ & $\begin{array}{l}\text { ProGr } \\
\text { r809 }\end{array}$ & $\begin{array}{l}\text { Uso } \\
\text { I809 }\end{array}$ & $\begin{array}{l}\text { VALOR } \\
\text { I809 }\end{array}$ \\
\hline direita & 03 & A & $\begin{array}{l}\text { Joaquim } \\
\text { Joze } \\
\text { Oliveira }\end{array}$ & Negociante & I & & & & proprio & sobrado & L+ra & misto & 38400 \\
\hline direita & 04 & A & $\begin{array}{l}\text { Cap. } \\
\text { Gabriel } \\
\text { Fernandes } \\
\text { Cantinho }\end{array}$ & Comerciante & 14 & 3 & & & proprio & sobrado & L+ra & misto & 38400 \\
\hline direita & 05 & A & $\begin{array}{l}\text { Manoel } \\
\text { de Oliveira } \\
\text { Cardoso }\end{array}$ & & & & $\begin{array}{l}\text { Ten. } \\
\text { Mathias } \\
\text { Joze de } \\
\text { Oliveira }\end{array}$ & [comerciante] & alugado & sobrado & L+ra & misto & 48000 \\
\hline direita & 06 & A & $\begin{array}{l}\text { Mosteiro } \\
\text { de São Bento }\end{array}$ & religioso & & & $\begin{array}{l}\text { Alferes } \\
\text { Luiz } \\
\text { Antonio } \\
\text { do Valle }\end{array}$ & [comerciante] & alugado & sobrado & L+ra & misto & 57600 \\
\hline
\end{tabular}




\begin{tabular}{|c|c|c|c|c|c|c|c|c|c|c|c|c|c|}
\hline $\begin{array}{l}\text { RUA } \\
\text { I809 }\end{array}$ & $\begin{array}{l}\text { N } \\
1809\end{array}$ & QuAdra & Prop I809 & Perf I789 & $\begin{array}{l}\text { Escravos } \\
\mathbf{P}\end{array}$ & $\begin{array}{l}\text { AGRE } \\
\text { P }\end{array}$ & INQ 1809 & Perf InQ & $\begin{array}{l}\text { Proprio } \\
\text { AL }\end{array}$ & $\begin{array}{l}\text { TIPO } \\
\text { I809 }\end{array}$ & $\begin{array}{l}\text { Progr } \\
\text { r809 }\end{array}$ & $\begin{array}{l}\text { Uso } \\
\text { I809 }\end{array}$ & $\begin{array}{l}\text { VALOR } \\
\text { I809 }\end{array}$ \\
\hline direita & 09 & B & $\begin{array}{l}\text { Manuel } \\
\text { Joaquim } \\
\text { deVasconcellos }\end{array}$ & & & & & & proprio & $\begin{array}{l}\text { terrea } \\
\text { (falsa) }\end{array}$ & L & loja & 26880 \\
\hline direita & 08 & B & $\begin{array}{l}\text { Cap. José } \\
\text { Pinto } \\
\text { Tavares }\end{array}$ & $\begin{array}{l}\text { Negociante } \\
\text { de Ferragens }\end{array}$ & & & & & proprio & sobrado & $L+r a$ & misto & 30720 \\
\hline direita & Io & C & $\begin{array}{l}\text { Cel. } \\
\text { Joaquim Jozé } \\
\text { dos Santos }\end{array}$ & & & & & & & & & & \\
\hline
\end{tabular}

Figura 6 - Pormenores da primeira quadra da Rua Direita contígua ao Largo da Sé.Dados da Décima Urbana de I809 espacializados pela autora por meio do Quantum GIS na Planta da cidade de São Paulo de I844-I847 de Carlos Bresser. BNRJ

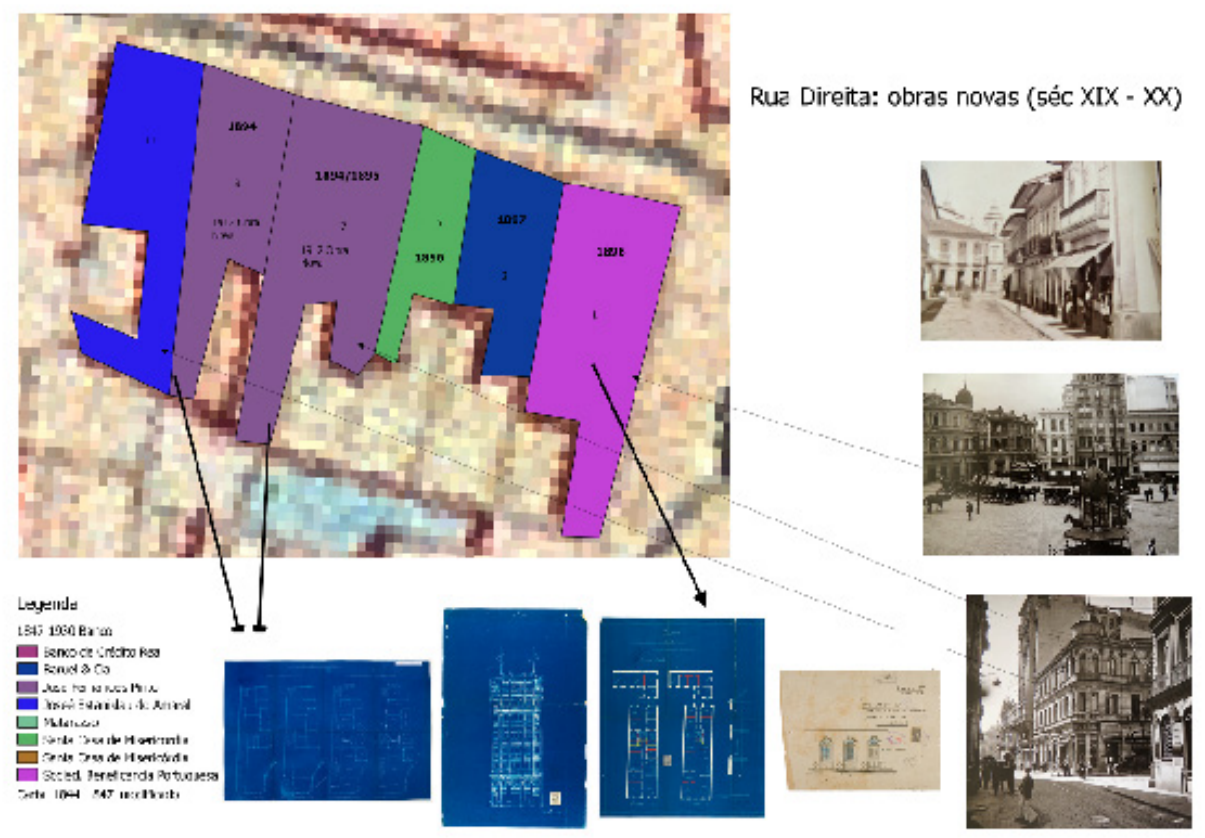

Figura 7-Transformações realizadas na primeira quadra da Rua Direita contígua ao Largo da Sé, entre I894-I896 e em I9I2.Permissões de construção da Série Obras Particulares do Arquivo Histórico de São Paulo entrecruzadas às fotos de época, espacializadas pela autora por meio do Quantum GIS na Planta da cidade de São Paulo de I844-I847 de Carlos Bresser. Original pertencente à BNRJ. 


\section{DE TRÊS A QUATRO CIDADES EM UM SÉCULO}

A dinâmica de mutação da cidade é incomum, e nossa tese é que o investimento estatal foi bastante inferior ao do capital privado, responsável pela concreta destruição e reconstrução do velho centro de taipa de pilão e pela introdução de novos usos e hábitos urbanos nos espaços, desde então um excelente negócio. Edifícios de tijolos e uso misto passaram a mesclar salas de escritórios e consultórios, moradias, lojas, charutarias, restaurantes e cafés, substituindo os imóveis de taipa de pilão e taipa de mão predominantemente residenciais no período colonial.

As atividades terciárias exigidas pela "metrópole do café" cresceram exponencialmente. Entre I776 e I883, a cidade passou de 207 indivíduos envolvidos com o setor para I.055 (em I798), I.9I6 (em I836) e 36.90I (em I893). Em I883, São Paulo contava com 69 advogados, 32 médicos-cirurgiões, Io engenheiros, 3 agrimensores, 33 empreiteiros de obras e 4 mestres de obras. De I30 casas de comércio existentes em I883, passou para 5.832, em I92I-I922 (292 de artigos de importação, I06 confeitarias e pastelarias, 22 perfumarias, 86 joalherias, 32 relojoarias, 62 papelarias, I52 charutarias, I5 casas importadoras de automóveis, 30 estabelecimentos bancários, além de diversos hotéis) ${ }^{26}$.

$\operatorname{Dados}^{27}$ evidenciam um explosivo aumento dos preços dos terrenos no "triângulo central” (ruas XV de Novembro, Direita e São Bento) entre I9I6 (I.000\$000 réis o $\mathrm{m} 2$ ), I936 (4.500\$000 réis o $\mathrm{m} 2$ ) e I943 (8.000\$0oo réis o m2), o que é produto e vetor (numa relação dialética) da contínua aceleração das demandas, das transformações arquitetônicas e urbanísticas e especialização ali do comércio e dos serviços de luxo. Constatamos que o valor do $\mathrm{m} 2$ no "perímetro central ou comercial" era altíssimo comparativamente às outras zonas da cidade. Em I9I4, o m2 nas ruas XV de Novembro, Direita e São Bento tinha um valor médio de I:000\$000 réis, ao passo que nos arredores imediatos decaía para $165 \$ 000$ réis, chegando a $23 \$ 500$ réis o m2 no "perímetro urbano"28. No "perímetro suburbano" chegava a 3\$000 réis o $\mathrm{m} 2$, atingindo o valor de Ioo réis no "perímetro rural". Também o valor locatício tornou-se muito atraente na área central, chegando a ser dezesseis vezes mais alto que nos subúrbios da cidade. Esses dados explicam o interesse dos estratos sociais de maior poder aquisitivo em investir no centro, construindo imóveis de aluguel cada vez mais verticalizados. Explicam, inclusive, o interesse do poder público (integrado por membros dessa mesma elite financeira) em investir em grandes obras de embelezamento e melhoramentos urbanos.

A feliz metáfora cunhada por Benedito Lima de Toledo nem sempre se aplica a todos os imóveis. Em alguns casos as "três cidades em um século" foram quatro. Vemos edificações recém-construídas serem demolidas em poucas décadas para dar lugar a novos prédios maiores e mais altos. Esse é o caso do Edifício Guinle citado

26 BUENO, B. P. S. São Paulo: um novo olhar sobre a história. A evolução do comércio de varejo e as transformações na vida urbana. São Paulo: Via das Artes, 20I2, p. 36.

27 R. C. BRITO. Cadastro imobiliário de São Paulo I937-I938, I938 apud BUENO, Beatriz. Aspectos do mercado imobiliário em perspectiva histórica. São Paulo, I809-I950. São Paulo: FAU/USP, 2008, p. I25.

28 GLEZER, R. São Paulo, cem anos de perímetro urbano. História (São Paulo), v. I3, p. I55-I66, I994. 
anteriormente que substituiu outros dois construídos I8 anos antes, assim como da nossa primeira Galeria de Cristal - semelhante às Passagens de Paris e à Galeria Vittorio Emanuele, de Milão - projetada por Max Hehl para o visionário alemão Cristiano Webendoerfer, inaugurada em I900 e demolida em I924 para abrigar a sede do Banco Comercial de São Paulo, projetado pelo Escritório Ramos de Azevedo \& Cia. Esse é o caso também da sede do Banco Francês e Italiano, construído em I9I8, que implicou a demolição de um belo edifício construído apenas sete anos antes para o conde Álvares Penteado, com projeto assinado pelo arquiteto sueco Carlos Ekman em I9II, bem como do imóvel de Jacques Netter, construído em I896 e demolido em 1932 para ceder lugar a outro mais alto29. Podemos citar também o caso do belo Banco di Napoli edificado para João Brícola pelo arquiteto Samuel das Neves em I9I2, substituído pelo igualmente elegante Banco Português do Brasil projetado pelo Escritório F. P. Ramos e Azevedo \& Cia. em I9I9.

\section{A VELHA OLIGARQUiA REINA ENTRE OS PROPRIETÁRIOS}

Os imóveis trocaram de mãos entre I809 e I9I4, mas a velha oligarquia seguiu sendo a proprietária majoritária no perímetro central da cidade, promovendo a sua demolição e reconstrução.

A espacialização das permissões de construção localizadas no Arquivo Histórico de São Paulo, dos impostos prediais de I886 e I9I4 (Tabelas I e 2), bem como dos Almanaques, sugere que, nessa época, a velha oligarquia paulistana de "empresários e capitalistas" envolveu-se com todo tipo de negócios (fazendas de café, bancos, obras de urbanização, serviços urbanos, fábricas e imóveis para renda de aluguel). Muitos são herdeiros das elites coloniais, como os Souza Queiroz, os Prado, os Toledo Lara, por exemplo. Entre os Alvares Penteado, os Queiroz Telles, os Prado, os Dumont Villares, os Souza Queiroz, os Prates e os Toledo Lara, sobressaem alguns imigrantes vinculados ao comércio (Rizkallah Jorge Tahan - Casa da Boia; Humberto e José Zucchi - Chapelaria; Manoel Garcia da Silva - dono da Loja do Japão e loteador do Jardim Europa), às fábricas (Francisco Matarazzo), aos bancos (os Levy e Luiz Medici), aos loteamentos (Burchard, Glette e Nothmann), por vezes aparentados aos velhos barões por matrimônio. Nota-se que os novos edifícios construídos no período destinavam-se a fins exclusivamente rentistas e pertenciam na íntegra a uma mesma família, num tipo de organização que antecedeu a lógica condominial. Muitos ainda estão nas mãos dos herdeiros dos antigos donos até hoje.

29 BUENO, Beatriz. Aspectos do mercado imobiliário em perspectiva histórica. São Paulo, I809-I950. São Paulo: FAU USP, 2008, p. I20-I24. 

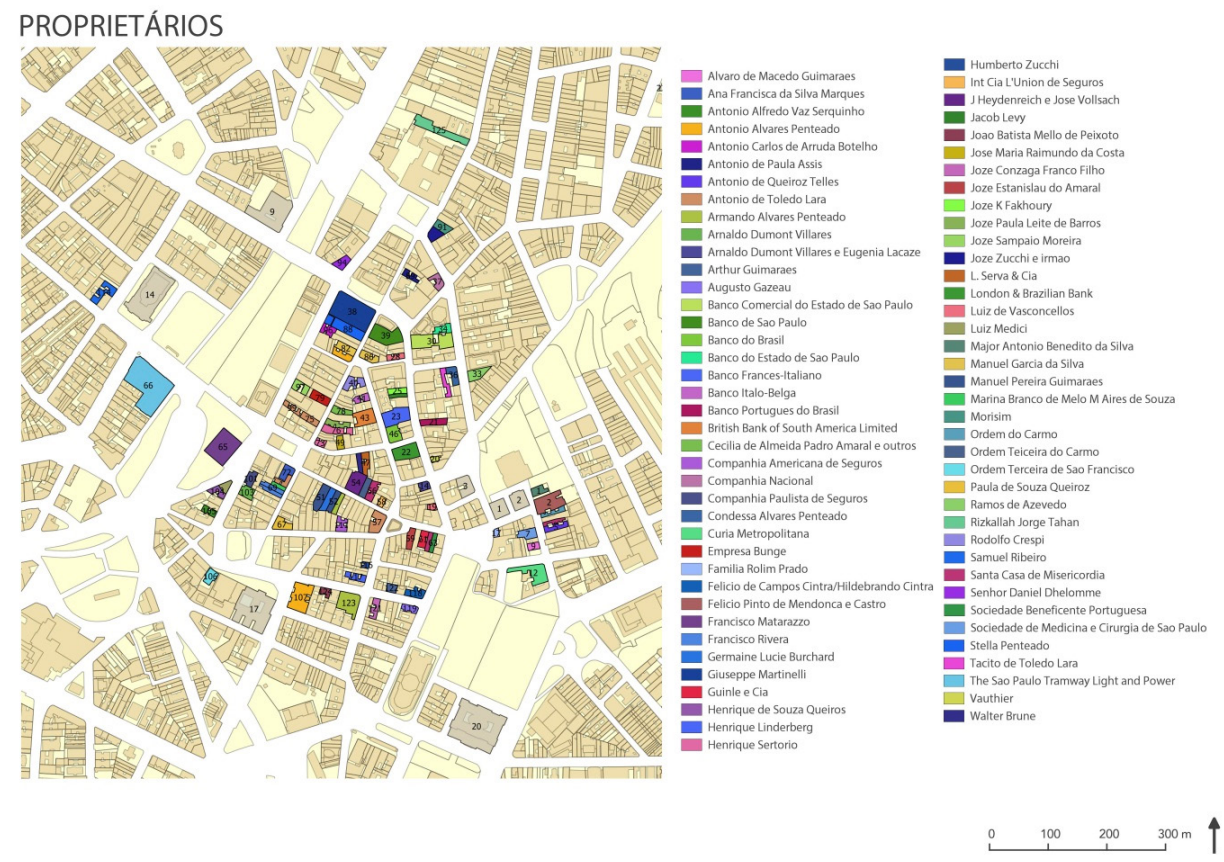

Figura 8 - Principais proprietários até meados do século XX. É visível a presença marcante da velha oligarquia. Mapa Digital da Cidade (2004-2006) - Prefeitura do Município de São PauloDestacam-se: Alvaro de Macedo Guimarães, Ana Francisca da Silva Marques, Antonio Alfredo Vaz Serquinho, Antonio Álvares Penteado, Antonio Carlos de Arruda Botelho, Antonio de Paula Assis, Antonio de Queiroz Telles, Antonio de Toledo Lara, Armando Álvares Penteado, Arnaldo Dumont Villares, Arnaldo Dumont Villares e Eugenia Lacaze, Arthur Guimarães, Augusto Gazeau, Cecilia de Almeida Prado Amaral e outros, condessa Álvares Penteado, Família Rolim Prado, Felicio de Campos Cintra, Felicio Pinto de Mendonça e Castro, Francisco Matarazzo, Francisco Rivera, Germaine Lucie Burchard, Giuseppe Martinelli, Guinle e Cia., Henrique de Souza Queiroz, Henrique Lindenberg, Henrique Sertorio, Humberto Zucchi, J. Heydenreich e José Volsach, Jacob Levy, João Batista Mello de Peixoto, José Maria Raimundo da Costa, José Gonzaga Franco Filho, José Estanislau do Amaral, Jozé Fakhoury, Joze Paula Leite e Bartos, Joze Sampaio Moreira, Joze Zucchi e irmão, L. Serva \& Cia., Luiz Lins de Vasconcellos, Luiz Medici, Major Antonio Benedito da Silva, Manuel Garcia da Silva, Manuel Pereira Guimarães, Marina Branco de Melo Aires de Souza, Paula de Souza Queiroz, Ramos de Azevedo, Rizkallah Jorge Tahan, Rodolfo Crespi, Samuel Ribeiro, Daniel Dhelomme, Stella Penteado, Tacito de Toledo Lara, Vauthier, Walter Brune 
TABELA I - IMPOSTO PREDIAL 1886

Proprietários maiores detentores de imóveis no centro de São Paulo

\begin{tabular}{|c|c|c|}
\hline Proprietário & Número de imóveis & $\begin{array}{l}\text { Imposto } \\
\text { a pagar }\end{array}$ \\
\hline I Mosteiro de São Bento & 25 & $3: 054 \$ 260$ \\
\hline 2 Benedicto Antonio da Silva & 8 & $2: 207 \$ 520$ \\
\hline 3 Visconde de São Joaquim & 8 & $\mathrm{I}: 8 \mathrm{I} 4 \$ 400$ \\
\hline 4 Santa Casa de Misericórdia & I9 & I:I72\$320 \\
\hline 5 Antonia Joaquina dos Santos Silva & I8 & I:I50\$IO4 \\
\hline 6 Domingos de Paiva Azevedo & IO & I:I44\$IOO \\
\hline 7 Barão de Souza Queiroz & II & I:088\$700 \\
\hline 8 Antonio Pinto do Rego Freitas & 5 & I:06I\$760 \\
\hline $\begin{array}{l}9 \text { Ana Brandina Prado Pereira Pinto } \\
\text { (herdeira Barão de Iguape, } \\
\text { Antônio Prado) }\end{array}$ & 3 & I:044\$2I6 \\
\hline Io Recolhimento de Santa Thereza & 9 & $\mathrm{I}: 038 \$ 040$ \\
\hline II Bom Jesus de Nazareth & 3 & $907 \$ 200$ \\
\hline I2 Victor Nothmann & 5 & $8 \mathrm{I} 6 \$ 640$ \\
\hline I3 Francisco Justino Gonçalves de Andrade & 4 & $77 I \$ 480$ \\
\hline I4 Rodrigo Augusto da Silva & 2 & $735 \$ 840$ \\
\hline I5 Henrique Luiz Levy & 3 & $705 \$ 600$ \\
\hline I6 Conde de Três Rios & 3 & $654 \$ 240$ \\
\hline I7 Barão de Tatuhy & $\mathrm{I} 2$ & $645 \$ 280$ \\
\hline I8 Antonio Francisco de Azevedo & 3 & $638 \$ 400$ \\
\hline I9 Manoel Lopes de Oliveira & 4 & $635 \$ 040$ \\
\hline 20 Lydia Gezzi e Filho & 2 & $604 \$ 800$ \\
\hline 2I José Candido de Azevedo Marques & 2 & $604 \$ 800$ \\
\hline
\end{tabular}


TABELA 2 - IMPOSTO PREDIAL I9I3-I4

Proprietários maiores detentores de imóveis no centro de São Paulo

\begin{tabular}{|c|c|c|c|}
\hline & Proprietário & ro de imóveis & \\
\hline I & Germaine Burchard & I8 & $54: 802 \$ 660$ \\
\hline 2 & Conde de Toledo Lara & I5 & $42: 410 \$ 400$ \\
\hline 3 & Conde de Prates & 24 & $34: 733 \$ 400$ \\
\hline 4 & Manoel Garcia da Silva & 9 & $30: 031 \$ 400$ \\
\hline 5 & Mosteiro de São Bento & 23 & $26: 794 \$ 000$ \\
\hline 6 & Conde Álvares Penteado & I3 & $25: 603 \$ 840$ \\
\hline 7 & Banco Alemão & 2 & I8:480\$000 \\
\hline 8 & Conde A. P. Pinto & $\mathrm{I}$ & $I 4: 322 \$ 000$ \\
\hline 9 & Luiz O. Lins Vasconcellos & 7 & I4:043\$800 \\
\hline IO & Claudio M. Soares & 3 & I2:472\$0 o0 \\
\hline II & Joaquim Q.C. Mattoso & $I$ & II:088\$000 \\
\hline I2 & Martinho Prado (herança) & I & IO:I64\$000 \\
\hline I3 & Antenor A.V. Cerquinho & 4 & $9: 886 \$ 800$ \\
\hline I4 & João Motta G. Cesar & 3 & $9: 868 \$ 800$ \\
\hline I5 & Francisco Sampaio Moreira & I2 & $7: 840 \$ 800$ \\
\hline I6 & José Sampaio Moreira & 3 & $7: 837 \$ 600$ \\
\hline I7 & Conde São Joaquim & 8 & $7: 669 \$ 200$ \\
\hline I8 & Frederico Glette (herança) & $I$ & $7: 392 \$ 000$ \\
\hline I9 & Luiz A.C. Galvão & 7 & $6: 612 \$ 600$ \\
\hline 20 & José Borges Figueiredo & 6 & $6: 588 \$ 120$ \\
\hline $2 I$ & Santa Casa de Misericórdia & I8 & ISENTO \\
\hline
\end{tabular}

\section{OS LOCATÁRIOS EM GERAL ERAM COMERCIANTES ESTRANGEIROS}

As novas edificações construídas na virada do século XIX para o XX envolviam, sobretudo, programas de uso misto. Pudemos constatar em incursões aos Almanaques que o comércio a partir de I870 foi obra de estrangeiros, no entanto, a nosso ver, esses recém-chegados não tiveram inicialmente capital para edificar a sede dos seus negócios, alugando-os da velha oligarquia.

Na Décima Urbana de I809 ficou claro que no período colonial o negociante reunia num único imóvel moradia e loja, em geral sendo proprietário dele. O Imposto Predial de 1876 revelou que apenas Adolpho Nagel, Gustavo Sydow e Henrique Fox eram estrangeiros proprietários de imóveis no centro. A velha oligarquia parece ter seguido sendo proprietária dos principais imóveis dali, mesclando-se muito 
paulatinamente a segmentos estrangeiros vinculados a ramos mais rentáveis, como ferrovias, por exemplo. Esse é o caso de Guilherme Rudge, solitário em meio ao baronato predominante, mas aparentado aos Álvares Penteado e aos Queiroz Telles. Entre a aristocracia, destacam-se: barão de Itapetininga, barão de Piracicaba, barão da Silva Gameiro, barão de Sousa Queiroz, barão de Tietê, barão de Três Rios, baronesa de Limeira, em meio a nomes da velha aristocracia de fins do XVIII e início do século XIX, como Manoel Rodrigues Jordão e Manoel Rodrigues Villares (Imposto Predial de I876).

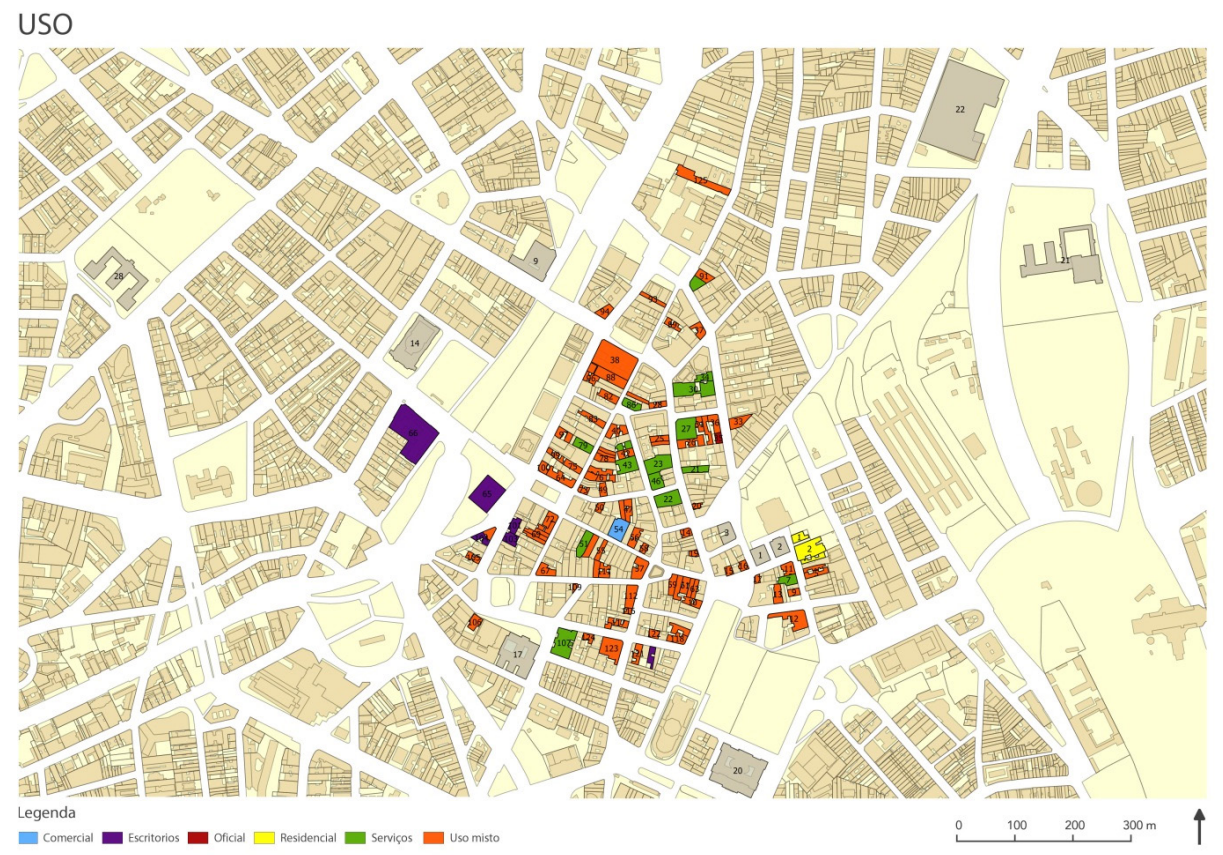

Figura 9- Uso dos imóveis: azul, exclusivamente comercial; verde, serviços (sobretudo bancos); laranja, uso misto; amarelo, exclusivamente residencial; roxo, uso exclusivo de escritórios sede de grandes empresas. Mapa Digital da Cidade (2004-2006) - Prefeitura do Município de São Paulo.

No Imposto Predial de 1886 vemos o universo ampliar-se, mas, comparativamente aos dados publicados no Almanaque de I890, poucos estrangeiros inserem-se na lista de proprietários no centro, predominando ainda a velha oligarquia paulistana. Exceções são: João Adolpho Schritizmeyer, Domingos Paiva de Azevedo, José Elias Paiva, Luiz Bamberg, Adolpho Nagel, Henrique Luiz Levy e Jorge Seckler, só para citar os mais conhecidos. Em I886, o centro parece manter-se nas mãos de um grupo social antigo, muitos dos nomes identificáveis desde a Décima Urbana de I809: barão de Piracicaba, visconde de Vergueiro, Francisco José de Sampaio, José Antônio de Oliveira Mendes, Anna Brandina Prado Pereira Pinto, Maria da Glória Moura Jordão, dr. Raphael Tobias de Aguiar, conde de Três Rios, Maria Cantinho Gavião Peixoto, 
visconde de São Joaquim, barão de Souza Queiroz, Antônio Pinto do Rego Freitas, baronesa de Limeira, Bernardo Avelino Gavião Peixoto, Raphael Aguiar Paes de Barros, conselheiro Antônio da Silva Prado, Elias Antônio Pacheco Chaves, Eleutério da Silva Prado, Firmino José Barbosa, José Arouche de Toledo, Eduardo Prates, só para citar alguns, em meio às ordens religiosas e irmandades laicas, com destaque sempre para o Mosteiro de São Bento.

Na Série Obras Particulares (I906-I9I4) o número de prédios para os quais foi solicitada autorização da Prefeitura para construção ou reforma por comerciantes estrangeiros elevou-se consideravelmente, embora ainda muito aquém dos estabelecimentos divulgados nos Almanaques. Comerciantes que solicitaram autorização de construção ou reforma no período estudado foram: Worms Irmãos, Luiz Bamberg, Antonio Luiz Garraux, Camisaria Especial, P. Birelmayer e Carlos Castellões, Fasano e Fazzini, Brasserie Paulista, Alcides Pertica, Luiz Levy, Carvalho Ramos \& Cia., Silvestre Noschese, o boticário Gustavo Shaw, Falchi Gianini e Cia., Oppenheim e Cia., Pharmacia Faraut, Comp. Brazil Express - Messenger Company, Heydenreich \& Irmãos, Bloch (Frères) e Cia., Cia. de Industria e Comercio Casa Tolle, Firma Guinle e Cia., Pharmacia Ipiranga, Enrique Paiva, Loja Marcondes Piratininga, Weissflog Irmãos \& Cia., Luiz Médici, Baruel e Companhia, Casa Fretin, L. Grumbach \& Cia, Casa "Ao Preço Fixo", Guilherme Rathsam, Jorge Fuchs e Comp., entre outros menos conhecidos.

Defendemos a hipótese de que os comerciantes foram inquilinos e raramente proprietários das lojas e das moradias construídas nos andares superiores dos imóveis, ao menos no início das suas atividades. O descompasso entre o número de estabelecimentos divulgados nos Almanaques e aquele publicado nas listas de Imposto Predial ou nas permissões de construção (Série Obras Particulares do Arquivo Histórico de São Paulo) evidencia que os comerciantes - majoritariamente estrangeiros - não dispunham de capital para comprar ou construir, alugando de terceiros tanto as lojas como os apartamentos que estavam sendo edificados no centro da cidade.

\section{MORADIAS PERMANECEM NO CENTRO EM MEIO À PREDOMINÂNCIA DE IMÓVEIS DE USO MISTO PARA LOJAS E ESCRITÓRIOS: QUEM AS HABITA?}

Nas novas edificações predominou a opção por programas vinculados ao comércio e aos serviços, mas as moradias subsistem no centro ao menos nas primeiras duas décadas do século XX. A propaganda imobiliária veiculada nos jornais corrobora essas afirmações. A pergunta é a quem se destinavam esses apartamentos situados em edifícios de uso misto, mesclando lojas no térreo a moradia nos andares superiores? Nossa hipótese é que não se destinavam às elites que partiram para os novos bairros residenciais nos subúrbios, mas aos comerciantes estrangeiros.

Habituados a morar no centro das cidades de onde vieram, junto de seus negócios, ao que tudo indica esses imigrantes de raiz urbana seguiram o mesmo padrão no Brasil (mantendo contíguos moradia e trabalho), na contramão da elite social e econômica local, que aderiu aos novos bairros exclusivamente residenciais. A nosso 
ver, foram os estrangeiros majoritariamente os locatários tanto das lojas como de uma nova tipologia de apartamentos projetada no perímetro central, sobretudo a partir de I902, nos edifícios de uso misto. Os projetos localizados no Arquivo Histórico de São Paulo - AHSP evidenciam a presença recorrente desse programa edilício, só não sabíamos a que público se destinava. Os comerciantes - em geral estrangeiros - foram, a nosso ver, na sua maioria inquilinos tanto das lojas como dos modernos apartamentos ainda não incorporados ao gosto da oligarquia e das camadas médias nacionais acostumadas a morar em moradias individuais.

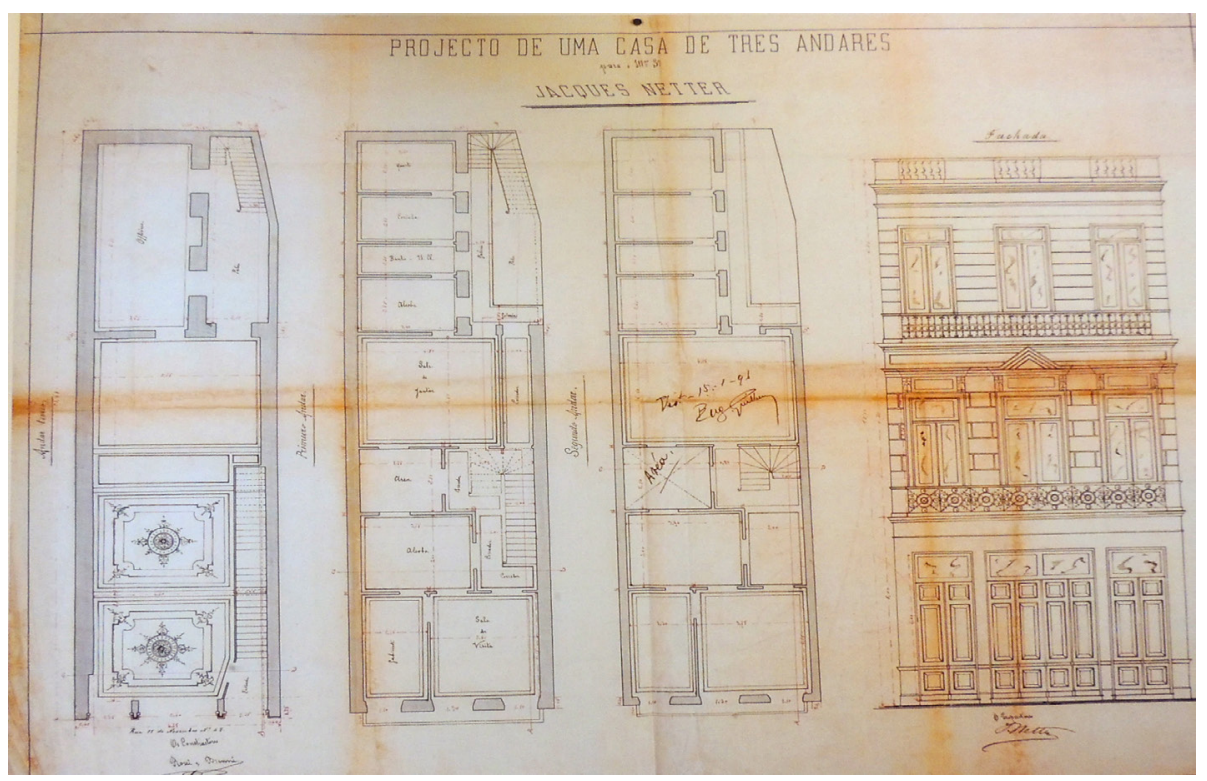

Figura Io - Tipologia recorrente no centro de São Paulo, o projeto mescla comércio e moradia. Rua XV de Novembro. Série Obras Particulares, I896. AHSP

\section{A Cidade CHEga Às alturas}

A cidade verticaliza-se induzida pela legislação, que estimula o alteamento com isenções de impostos. Resultado visível do boom da cafeicultura e da imigração, as obras de matriz higienista de "embelezamento e melhoramentos urbanos" foram foco da administração dos primeiros prefeitos de São Paulo - Antônio Prado, Raimundo Duprat e Washington Luís. Na Primeira República (I889-I930) a burocracia municipal se aparatou para orquestrar o processo de transformação da cidade, sendo criadas as seções de "Obras e Viação" e de "Polícia e Higiene" para tanto. A Seção de Obras e Viação foi coordenada ao longo de 27 anos pelo engenheiro politécnico Victor da Silva Freire e, a partir de I893, passou a exigir que as solicitações de pedidos para construção encaminhadas por particulares fossem acompanhadas por desenhos em planta, elevação e corte, que hoje integram a Série Obras Particulares do Arquivo 
Histórico de São Paulo ${ }^{30}$. O objetivo era verificar o cumprimento da legislação urbanística.

A legislação configurou um ideal de cidade, predominando certa homogeneidade de gabarito, à maneira da Paris haussmaniana. Enquanto o engenheiro politécnico Victor Freire esteve à frente da Diretoria de Obras da Prefeitura por 27 anos, o padrão imperou. O Código de Posturas de I886 regulou as seguintes alturas para os edifícios: primeiro pavimento $-5 \mathrm{~m}$; segundo pavimento $-4,88 \mathrm{~m}$; terceiro pavimento $-4,56$ $\mathrm{m}$. Nesse sentido, um edifício de três pavimentos atingiria no máximo I7 $\mathrm{m}$. Para os edifícios com mais andares, o primeiro pavimento deveria ter $5 \mathrm{~m}$, o segundo 4,80 $\mathrm{m}$ e o terceiro 4,50 m. As paredes deveriam ter um acréscimo de $15 \mathrm{~cm}$ a cada andar, sendo no térreo a de maior espessura. Eram também permitidas sobrelojas com gabarito mínimo de 2,5 $\mathrm{m}$ do soalho ao forro. A análise dos projetos permite entrever que nem sempre as medidas foram seguidas ao pé da letra, embora sem grandes distorções.

No entanto, após os anos I920 a cidade explodiu em altura, induzida por uma legislação urbanística que privilegiou as demandas de um mercado imobiliário cada vez mais aquecido, em resposta a uma cidade que não parava de crescer. $O$ concreto armado permitiu a verticalização, e os arranha-céus art déco seguiram padrões nova-iorquinos. Entre as décadas de I920 e I940 vários despontaram na paisagem, especialmente nas áreas onde incidiram as novas operações urbanísticas. A altura tornou-se cada vez mais sinônimo de modernidade, e muitos proprietários não hesitaram em pôr abaixo seus imóveis ecléticos recém-construídos e substituí-los por outros mais altos, pois havia demanda.

30 Sistema de Registro, Controle e Acesso ao Acervo - Sirca do Arquivo Histórico Municipal "Washington Luís", vinculado ao Departamento do Patrimônio Histórico da Secretaria Municipal de Cultura. Disponível em: www.projetosirca.com.br 


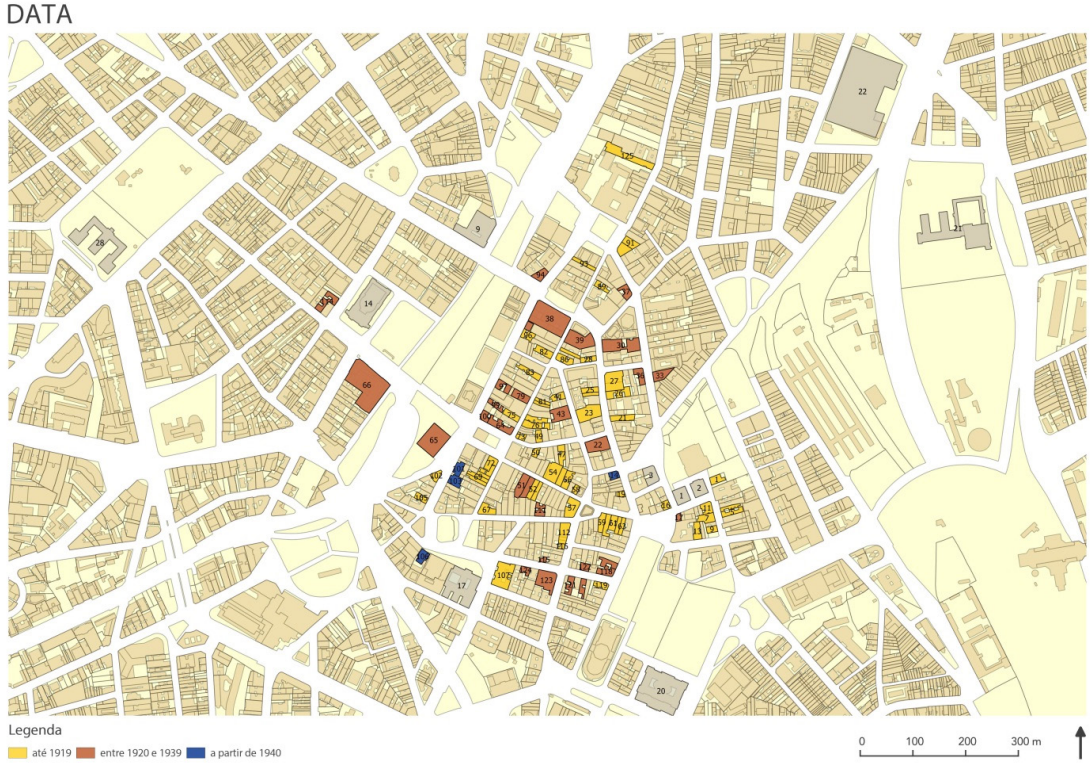

Figura II - Data das edificações: em amarelo, destacam-se os imóveis edificados antes de I9I9; em vermelho, os construídos entre I920 e I935; e, em azul, os edificados a partir de I940. Mapa Digital da Cidade (2004-2006) - Prefeitura do Município de São Paulo.

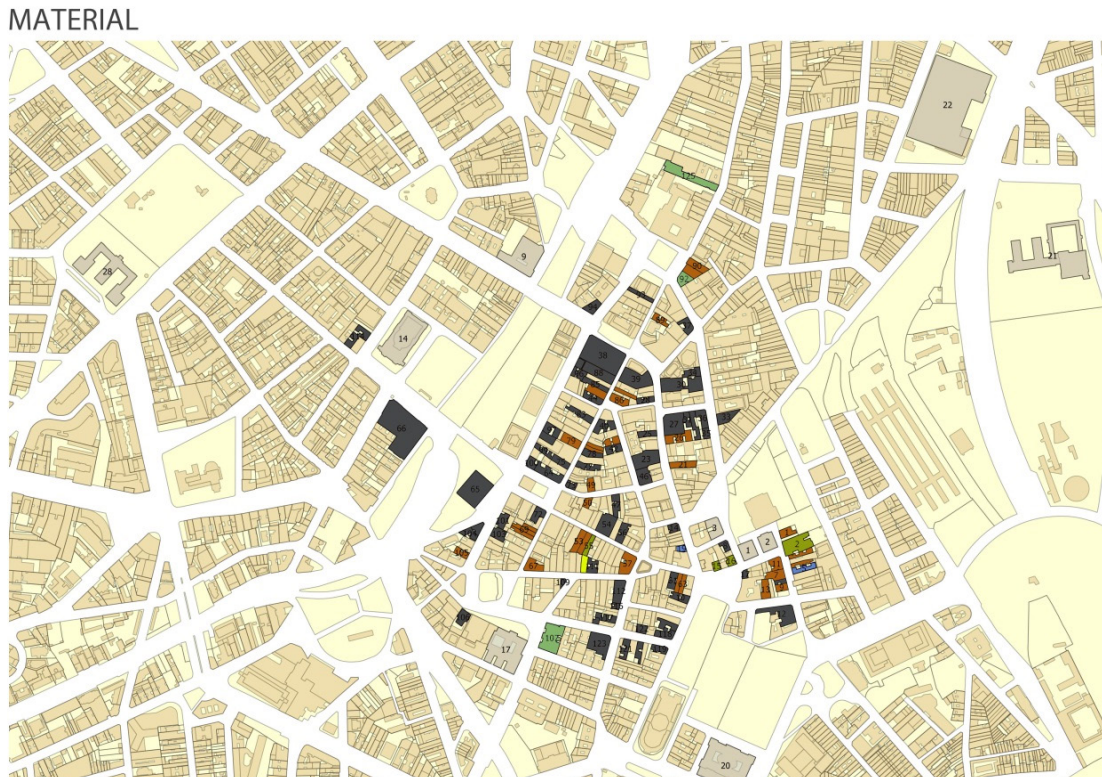

Figura I2 - Materiais, técnicas e sistemas construtivos: em preto, destacam-se os imóveis construídos de concreto e tijolo; em vermelho, os de estrutura de tijolo autoportante; em verde, os de tijolo e taipa. Mapa Digital da Cidade (2004-2006) - Prefeitura do Município de São Paulo 


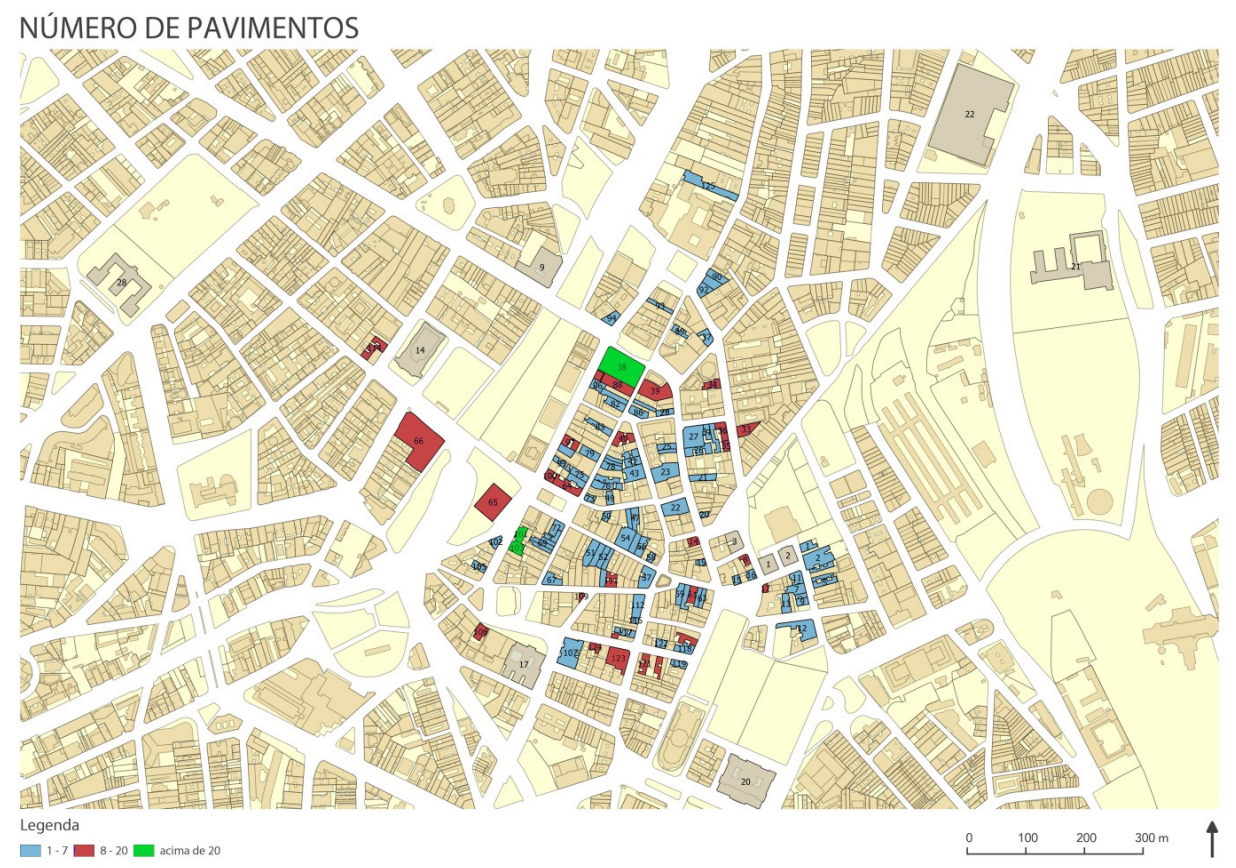

Figura I3 - Número de pavimentos: azul, I-7 andares; vermelho, 8-20 andares; verde, acima de 20 andares. Os mais altos situam-se junto à Rua Libero Badaró, área fronteira ao Plano de Remodelação do Parque do Anhangabaú. Mapa Digital da Cidade (2004-2006) - Prefeitura do Município de São Paulo.

\section{OS ARQUITETOS DO CENTRO}

Os projetos arquitetônicos revelam os profissionais, na sua maioria estrangeiros ou brasileiros que estudaram no exterior num momento de institucionalização do ensino da arquitetura em São Paulo (a Escola Politécnica de São Paulo e o Mackenzie College datam somente da década de I890). Raríssimos são os construtores não diplomados que assinaram projetos no centro. Os arquitetos deixaram epígrafes nas fachadas registradas no site Acervo Epigráfico Paulistano ${ }^{3 \mathrm{I}}$.

Surpreende a ação empresarial do Escritório Técnico F. P. Ramos de Azevedo,

3I ACERVO EPIGRÁFICO PAULISTANO. Projeto Paisagens tipográficas - a organização de um acervo das epígrafes arquitetônicas paulistanas. Pesquisa realizada por Ana Paula Gouveia (Instituto de Artes da Universidade Estadual de Campinas - Unicamp), Priscila Farias (Centro Universitário Senac e Faculdade de Arquitetura e Urbanismo - FAU da USP) e Patrícia Gatto (Centro Universitário Senac). Disponível em: <http:// www.iar.unicamp.br/lis/pat/index.htm>. 
Severo \& Villares ${ }^{2}$, contratado pelo estado para assinar as principais obras públicas - Secretaria da Fazenda (I886-I89I), Secretaria da Agricultura (I892-I896), antiga sede da Bolsa de Mercadorias (I933-I937), Quartel da Luz (I888-I892), Escola Normal (Caetano de Campos, I892-I894), Teatro Municipal (I903-I9II), Edifício dos Correios e Telégrafos (I920-I922), Palácio das Indústrias (I9II-I924), Mercado Municipal (I922-I933), Palácio da Justiça (I920-I933), Faculdade de Direito (I933) - entre cerca de 4.000 outras para particulares em quase Ioo anos de existência (I886-I980).

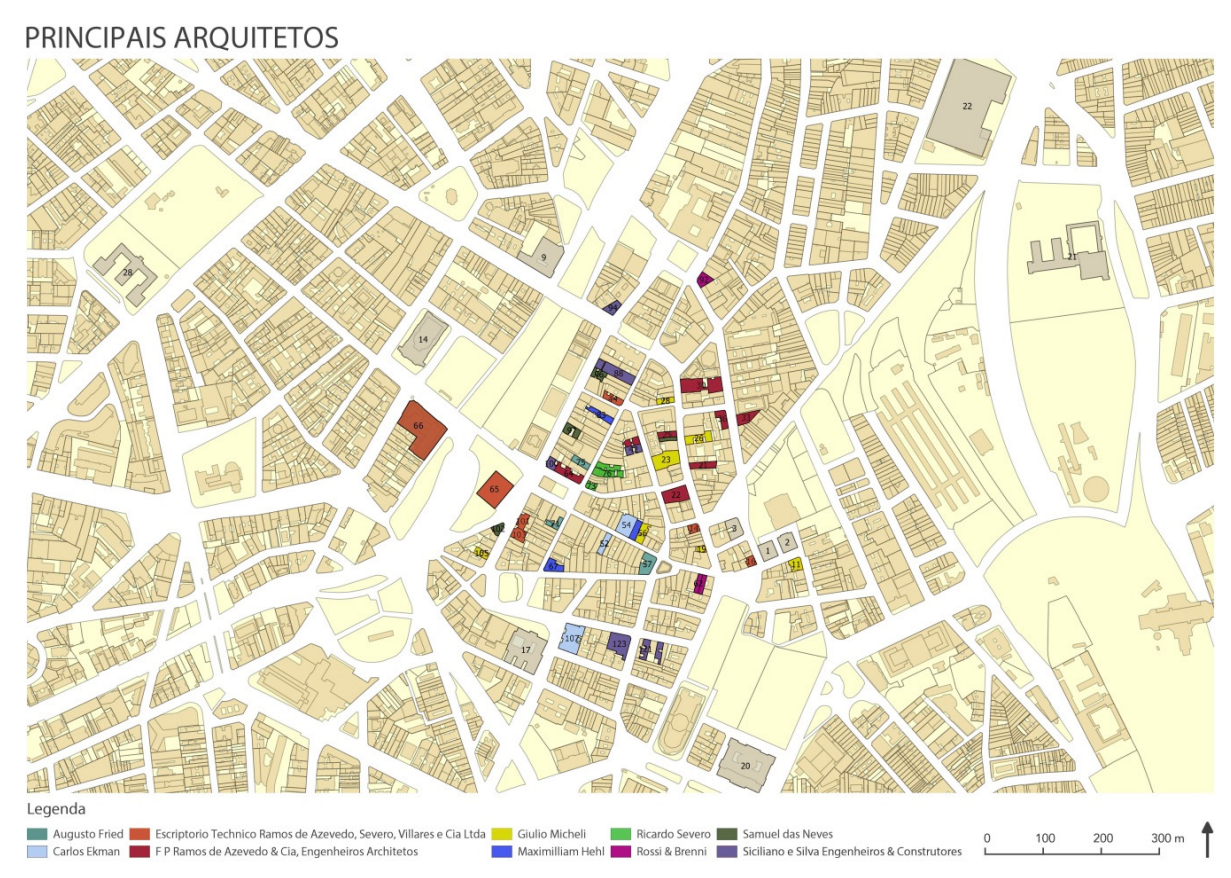

Figura 14-Os principais arquitetos das I20 edificações eleitas para estudo regressivo: Ramos de Azevedo (vermelho); Ricardo Severo (verde); Max Hehl (azul cobalto); Carlos Ekman (azul-claro); Augusto Fried (azul-escuro); Giulio Michelli (amarelo); Samuel das Neves (verde-musgo); Siciliano e Silva (roxo). Mapa Digital da Cidade (2004-2006) - Prefeitura do Município de São Paulo

\section{Conclusão}

Como já dissemos, boa parte das renovações foi obra da iniciativa privada, no entanto, embora motivados pelos lucros prometidos por um mercado imobiliário aquecido, os

32 BUENO, Beatriz. Escritório Ramos de Azevedo: a arquitetura e a cidade. São Paulo: Centro Cultural Correios, 20I5. (catálogo de exposição) 
resultados foram, a nosso ver, de qualidade. Das I2o edificações estudadas, a maioria mantém-se bem, o que nos permite demonstrar a qualidade das construções mesmo atendendo ao mercado imobiliário.

Tratava-se de um excelente negócio para os proprietários construírem imóveis cada vez mais verticalizados e multifuncionais, pois havia demanda, mas as obras foram feitas com projetos assinados pelos melhores profissionais da época, edificados em conformidade com uma legislação urbanística e sanitária que zelava pela qualidade do produto (garantindo pé-direito generoso, aberturas fartas, materiais construtivos de primeira). Os memoriais e projetos arquitetônicos hoje reunidos na Série Obras Particulares do Arquivo Histórico de São Paulo alicerçam tais afirmações. O resultado hoje é um importante patrimônio em vias de dilapidação que resiste ao tempo galhardamente a despeito de tanto descaso. Resiste porque foi feito sólido mesmo no âmbito de um efervescente mercado imobiliário rentista.

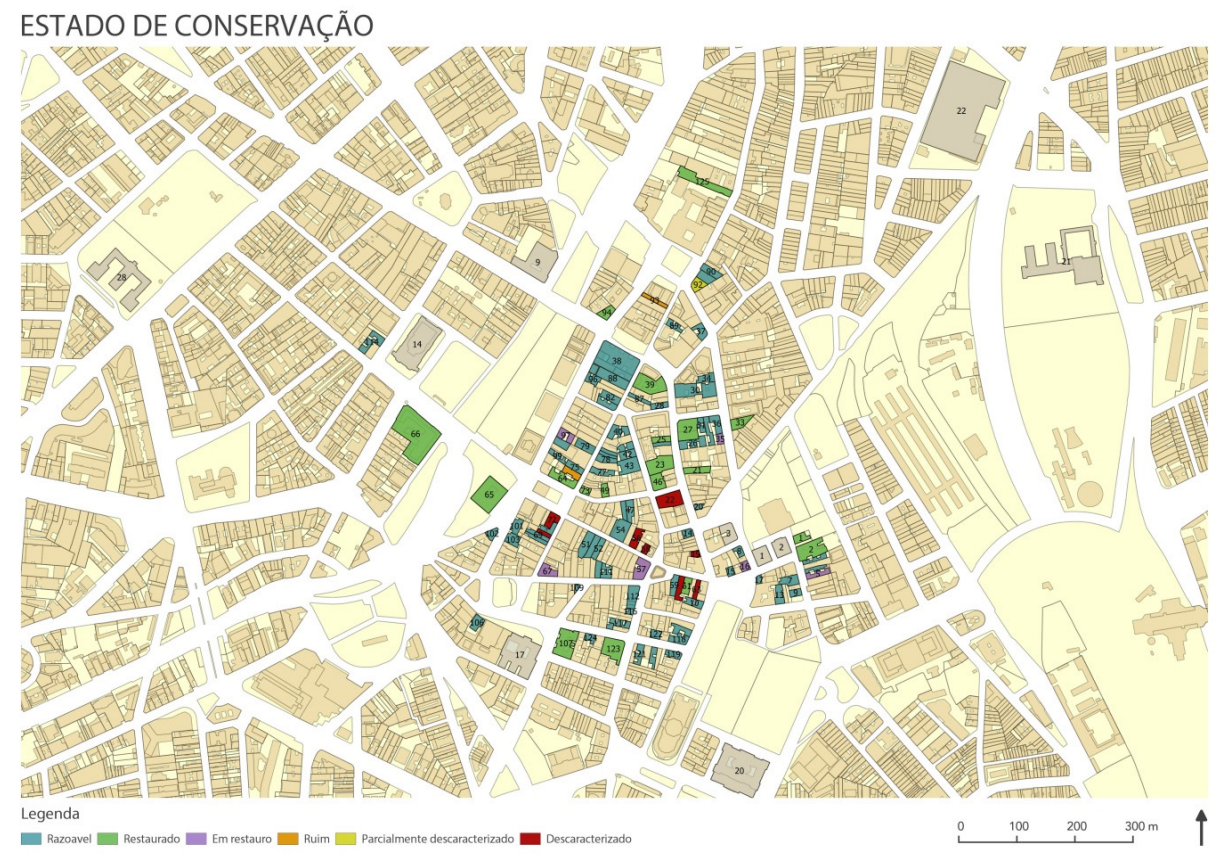

Figura I5 - Estado de conservação do conjunto de edificações eleitas para estudo regressivo: azul, razoável; verde, restaurada; roxo, em restauro; laranja, ruim; amarelo, parcialmente descaracterizada; vermelho, descaracterizada. Mapa Digital da Cidade (2004-2006) - Prefeitura do Município de São Paulo. 


\section{BEATRIZ PICCOLOTTO SIQUEIRA BUE-}

NO é professora do Departamento de História da Arquitetura e Estética do Projeto da Faculdade de Arquitetura e Urbanismo da Universidade de São Paulo - FAU/USP.

E-mail: bpsbueno@gmail.com

\section{REFERÊNCIAS BIBLIOGRÁFICAS}

BARBUY, H. A cidade-exposição. Comércio e cosmopolitismo em São Paulo, I860-I9I4. São Paulo: Edusp, 2006.

. Seguindo Militão pelas ruas da cidade. In: FERNANDES JR., Rubens; BARBUY, Heloisa; FREHSE, Fraya. Militão Augusto de Azevedo. São Paulo: Cosac Naify, 2012.

BOUDON, F.; CHASTEL, A.; COUZY, H.; HAMON, F. Système de l'architecture urbaine. Le quartier des Halles a Paris. Paris: Éditions du CNRS, I977. 2 v.

BRAUDEL, F. La Mediterranée et le monde mediterranéen à l'époque de Philippe II. (Ia. ed., I949). 5. ed. Paris: Armand Collin, I982, 2v.

. Civilisation matérielle. Economie et capitalisme, XVe-XVIIIe siècle. Paris: Armand Collin, I979, 3 v. BRITO, M. S. A participação da iniciativa privada na produção do espaço urbano. São Paulo I89o-I9II. São Paulo: FAU/USP, 2008.

BUENO, B. P. S. Tecido Urbano e mercado imobiliário em São Paulo; metodologia de estudo com base na Décima Urbana de I809. Anais do Museu Paulista: História e Cultura Material, n.I3, p. 49-99, 2005. . Aspectos do mercado imobiliário em perspectiva histórica. São Paulo, I809-I950. São Paulo: FAU/ USP, 2008.

. São Paulo: um novo olhar sobre a história. A evolução do comércio de varejo e as transformações na vida urbana. São Paulo: Via das Artes, 2012.

. Escritório Ramos de Azevedo: a arquitetura e a cidade. São Paulo: Centro Cultural Correios, 2015. (catálogo de exposição)

CAMPOS, C. M. Os rumos da cidade. Urbanismo e modernização em São Paulo. São Paulo: Senac, 2002.

GAUTHIEZ, B. \& ZELLER, O. Lyons, the spatial analysis of a city in the I7th and I8th centuries. Locating and crossing data in a GIS built from written sources. In: RAU, S. \& SCHÖNHERR, E. (Ed.). Mapping spatial relations, their perceptions and dynamics, lecture notes in geoinformation and cartography. Switzerland, Springer International Publishing, 20I4.

GLEZER, R. São Paulo, cem anos de perímetro urbano. História (São Paulo), v. I3, p. I55-I66, I994.

LÉFÈVRE, J. E. De beco a avenida. A história da Rua S. Luiz. São Paulo: Edusp, 2006.

LE GOFF, J. O apogeu da cidade medieval. São Paulo: Martins Fontes, I992.

REIS, N. G. Notas sobre a evolução dos estudos de história da urbanização e do urbanismo. Cadernos de Pesquisa do LAP, n. 29, I999.

ROLNIK, R. A cidade e a lei. Legislação, política urbana e territórios na cidade de São Paulo. 3. ed. São Paulo: Studio Nobel/ Fapesp, I998. 
SANTOS, M. Por uma geografia nova. 6. ed. São Paulo: Edusp, 2008 (Ia ed. I978).

SANTOS, M. A natureza do espaço. Técnica e tempo. Razão e emoção. 4. ed. São Paulo: Edusp, 2008 (Ia ed. I996).

SALERNO, L.; SPEZZAFERRO, L.; TAFURI, M. Via Giulia: una utopia urbanística del 500. Roma: Casa Editrice Stabilimento Aristide Staderini SPA, I973.

SCHLERETH, T. Cultural history er material culture: everyday life, landscapes, museums. Charlottesville: University Press of Virginia, I992.

TOLEDO, B. L. de. São Paulo: três cidades em um século. 2. ed. São Paulo: Duas Cidades, I983. 